\title{
Basic Psychological Need Satisfaction and Well-Being Across Age: A Cross-Sectional General Population Study among 1709 Dutch Speaking Adults
}

\author{
Johan Lataster ${ }^{1,2}$ (D) Jennifer Reijnders ${ }^{1}$ (D) Mayke Janssens ${ }^{1,2}$ (iD . \\ Marianne Simons $^{1}$ (D) . Sanne Peeters ${ }^{1,2}$ (D) . Nele Jacobs ${ }^{1,2}$ (D)
}

Accepted: 19 November 2021 / Published online: 31 January 2022

(C) The Author(s) 2022

\begin{abstract}
According to self-determination theory, individual well-being is universally dependent upon the satisfaction of three basic psychological needs: autonomy, competence and relatedness. This study set out to further elucidate the relationship between basic psychological need satisfaction (BPNS) and well-being across age by (i) more closely examining the age distribution of BPNS, and (ii) investigating whether BPNS is comparably associated with well-being across all ages, as predicted by the universality assumption, while taking into account variability in other demographic factors. A general population sample of Dutch speaking adults from The Netherlands and Belgium $\left(N=1709 ; M_{\text {age }}=48.6\right.$ years, $\mathrm{SD}=19.0$, range 18-97) filled out a cross-sectional online or paper-and-pencil survey questionnaire, providing self-reports of BPNS and well-being, using the Basic Psychological Need Satisfaction and Frustration Scale and Mental Health Continuum-Short Form, respectively. Data analyses consisted of initial visual inspection using LOESS smoothed curve plotting, and subsequent model testing using multiple regression analyses. When correcting for other demographic factors, results showed a positive linear relationship between age and autonomy satisfaction, no significant relationship between age and competence satisfaction, and a slight positive cubic relationship between age and relatedness satisfaction (initial 'peak', followed by a slight decline and 'dip', and steady rise for later ages). All basic psychological needs factors were positively linked to well-being in all domains, with associations generally comparable between adults of different ages, thus lending support to the universality assumption of self-determination theory. Despite distinct age distributions, all three basic psychological needs seem important for maintaining a sense of well-being throughout life.
\end{abstract}

Keywords Self-determination theory $\cdot$ Need fulfillment $\cdot$ Happiness $\cdot$ U-bend $\cdot$ Aging

Johan Lataster

johan.lataster@ou.nl

1 Department of Lifespan Psychology, Faculty of Psychology, Open University, P.O. Box 2960, 6401 DL Heerlen, The Netherlands

2 Department of Psychiatry and Psychology, School for Mental Health and Neuroscience, Maastricht University Medical Centre, Maastricht, The Netherlands 


\section{Introduction}

What constitutes human well-being throughout the lifespan? The current study aims to address this question from the perspective of self-determination theory (Deci \& Ryan, 2000, 2008; Ryan \& Deci, 2000), which states that individual well-being is universally dependent upon the satisfaction of three basic psychological needs: autonomy, competence and relatedness. What does the age distribution of basic psychological need satisfaction look like? And is the satisfaction of basic psychological needs indeed comparably associated with well-being across all ages? To answer these questions, the current study zooms in on the interplay of age, basic psychological need satisfaction, and well-being.

The human life course is characterized by inevitable changes and challenges in various domains (Baltes, 1987; Huber et al., 2011), and maintaining a sense of well-being by positively adapting to these is considered an important aspect of health and healthy aging (Beard et al., 2016; Fry \& Keyes, 2010; Huber et al., 2011; Keyes, 2014). Over the past decades, social science scholars have shown an increasing interest in identifying patterns of well-being across the lifespan, debating over the shape of the age distribution of well-being (in particular, whether it is U-shaped or not, see e.g. López Ulloa et al., 2013; Blanchflower \& Graham, 2020), and over factors that may explain observed differences in well-being across different ages (see: Diener et al. (2018), for a recent overview of the literature).

A prominent place in the latter line of research is held by the study of common environmental factors and external circumstances relating to well-being in different stages of the life cycle (e.g., Andrews \& Withey, 2012; Campbell et al., 1976; Cummins, 1996). The often reported 'midlife dip' in well-being (Blanchflower \& Graham, 2020), for instance, has been suggested to reflect financial and parental strains, as well as work-life balance struggles, which are typically present in this life phase (Cummins, 1996; Easterlin, 2006). However, environmental factors and circumstances seem to have altogether a relatively small impact on the experience of well-being (R. E. Lucas \& Diener, 2000), and associations between age and well-being remain significant when correcting for these factors (Blanchflower \& Oswald, 2008; Clark \& Oswald, 2006; Frey \& Stutzer, 2002), implying that differences in well-being across age do not merely reflect the impact of external circumstances (Diener et al., 2018; Myers \& Diener, 1996). Moreover, it is argued that the mechanisms linking such circumstances to individual well-being have a psychological basis (Campbell et al., 1976; Crawford Solberg et al., 2002; Easterlin, 2010; Veenhoven, 1991). The impact of parenthood on well-being, for instance, appears to depend on a tradeoff between increased negative emotions, economic and time constraints, and marital stress on the one hand, and increased meaning in life, basic need satisfaction, positive emotions, and enhanced social roles, on the other (Nelson et al., 2014). Such indirect effects of external circumstances on well-being have also been suggested for low economic power, which may affect well-being through psychological challenges in the domains of individual autonomy and social integration (Di Domenico \& Fournier, 2014). Similarly, experiencing sufficient time for balancing work and social roles only benefits well-being when psychological needs are met within that time (Gröpel \& Kuhl, 2009).

Thus, the impact of life events and circumstances on individual well-being may depend on the extent to which these factors are experienced as psychologically frustrating or fulfilling, in line with self-determination theory (hereafter: SDT, Deci \& Ryan, 2000, 2008; Ryan \& Deci, 2000), a widely researched and empirically validated metatheoretical framework of human-environment interaction. According to SDT, individual well-being depends on the fulfillment of three innate and universal psychological needs: the need for autonomy (the 
experience of full willingness and volition), competence (feeling effective and capable), and relatedness (intimacy and genuine connection with others) (Deci \& Ryan, 2000; Ryan $\&$ Deci, 2000). Although these basic psychological needs may differ in salience between individuals and across life phases (Chen et al., 2015; Hahn \& Oishi, 2006), their satisfaction is thought to be universally linked to optimal development and well-being in adults of all ages (Deci \& Vansteenkiste, 2004; Ryan et al., 1995), also referred to as the 'universality assumption' (Neubauer et al., 2018; van Assche et al., 2018). Studies in different age cohorts—among adolescents (e.g., Tian et al., 2014), adults (e.g., Ryan et al., 2010), and elderly (e.g., Ferrand et al., 2014)—have indeed consistently demonstrated strong associations between basic psychological need satisfaction and well-being. In addition, in a small sample of young, middle-aged, and older Canadian adults, overall psychological need satisfaction appeared to be comparably associated with well-being across age groups, supporting the universality assumption (Mackenzie et al., 2018). However, there is relatively scant literature which systematically investigates the age distribution of satisfaction of the three separate basic psychological needs-autonomy, competence, and relatedness-, and whether associations between satisfaction of each of these needs and well-being are indeed similar across age.

So far, only one study among Hungarian adults has investigated the age distribution of basic psychological needs. Global levels of need fulfillment were shown to remain relatively stable across age, but more complex patterns appeared when looking at different psychological needs separately (Tóth-Király et al., 2018). Specifically, whereas age was not related to relatedness fulfillment, findings pointed towards a linear increase in autonomy fulfillment with age, but suggested a concave (inverted $U$ ) relationship between competence fulfillment and age (Tóth-Király et al., 2018). However, apart from gender, this study did not systematically account for demographic variability (e.g. employment, income, relationship status) in psychological need fulfillment, and it therefore remains unclear to what extent the reported findings can be attributed to age, per se. In addition, this study did not investigate associations between basic psychological need satisfaction and well-being across age. While the universality hypothesis predicts that these associations are comparable between adults of different ages, lifespan psychology theories, such as socioemotional selectivity theory (Carstensen, 1992; Carstensen et al., 1999) and gerotranscendence theory (Tornstam, 1997), suggest that certain needs may be more closely linked to well-being at some ages compared to others, due to a shift in goals associated with particular life stages (Freund, 2017). For instance, with age, adults may become increasingly systematic in the shaping of social networks to satisfy their emotional needs, which may imply that satisfaction of the need for relatedness may be more strongly related to well-being in older vs. younger adults, as has been demonstrated for relatedness and physical health (Choi et al., 2018). While a number of studies in specific age groups indeed suggest that not all needs are equally important for well-being at each life phase (Ferrand et al., 2014; Henning et al., 2019; Vanhove-Meriaux et al., 2018), results are contradictory, and do not provide a comprehensive view of the relationship between basic psychological need satisfaction and well-being across age.

The current study therefore aims to extend previous findings by (i) exploring the age distribution of satisfaction of the three separate basic psychological needs in a sample of Dutch adults of different ages, and (ii) investigate whether satisfaction of each of the three basic psychological needs is indeed comparably associated with well-being across all ages, as predicted by the universality assumption, while taking into account variability in other demographic correlates of basic psychological need satisfaction and/or wellbeing, specifically: gender (Petrillo et al., 2015; Tóth-Király et al., 2018), educational 
level (Blanchflower \& Oswald, 2004), employment (Dolan et al., 2008; Zechmann \& Paul, 2019), income (Di Domenico \& Fournier, 2014; Morgan et al., 2015), marital status (Demir \& Davidson, 2013; Grover \& Helliwell, 2019), having children (Nelson et al., 2014), living situation, and physical and mental illness (Dolan et al., 2008; Ng et al., 2012).

\section{Method}

\subsection{Participants and Procedure}

The sample for this cross-sectional study consisted of Dutch speaking adults from the general population, living in The Netherlands or in Belgium. A total number of 2538 participants were recruited by graduate students of the Open University of The Netherlands through personal contact, online social media, and visits to retirement homes. Study entry criteria were (i) aged $18+$ years, and (ii) sufficient command of the Dutch language to understand instructions and provide informed consent. The study was approved by the local research ethics committee of the Open University of The Netherlands, and was carried out in accordance with APA Ethical Standards (American Psychological Association, 2002) regarding research with human participants. Participation in the study was voluntary and not incentivized by extrinsic motivators or rewards. All participants gave informed consent after being fully informed about the study and having had the opportunity to have any questions answered.

In order to maximize response, a hybrid data collection approach was used (Leeuw, 2005; McMahon et al., 2003), giving participants the option of either answering to an online or paper version of a short survey questionnaire, both distributed by graduate students. Of the 2358 participants that were recruited, 1831 accessed the online survey webpage, whereas 527 participated in the paper version of the survey. Completion rates (i.e. the percentage of recruited participants providing a complete survey response) were $66 \%$ $(n=1211)$ for the online survey, and $94 \%(n=498)$ for the paper version. The final study sample, thus, consisted of 1709 individuals ( $72 \%$ of total recruited).

\subsection{Sample Characteristics}

See Table 1 for detailed demographic characteristics of the final sample, displayed separately for different age groups, together with descriptive information regarding the main research measures (i.e., well-being and basic psychological need satisfaction).

\subsection{Measures}

\subsubsection{Basic Psychological Need Satisfaction and Frustration Scale}

The validated Dutch Basic Psychological Need Satisfaction and Frustration Scale (BPNSFS; Chen et al., 2015) was used to measure global basic psychological need satisfaction, as well as domain-specific need satisfaction and frustration in the subdomains of autonomy, competence, and relatedness. The BPNSFS consists of twenty-four propositions (e.g., I feel my choices express my true self; I feel forced to do many things I wouldn't choose to do), to which participants responded using a five-point Likert-type scale, ranging 


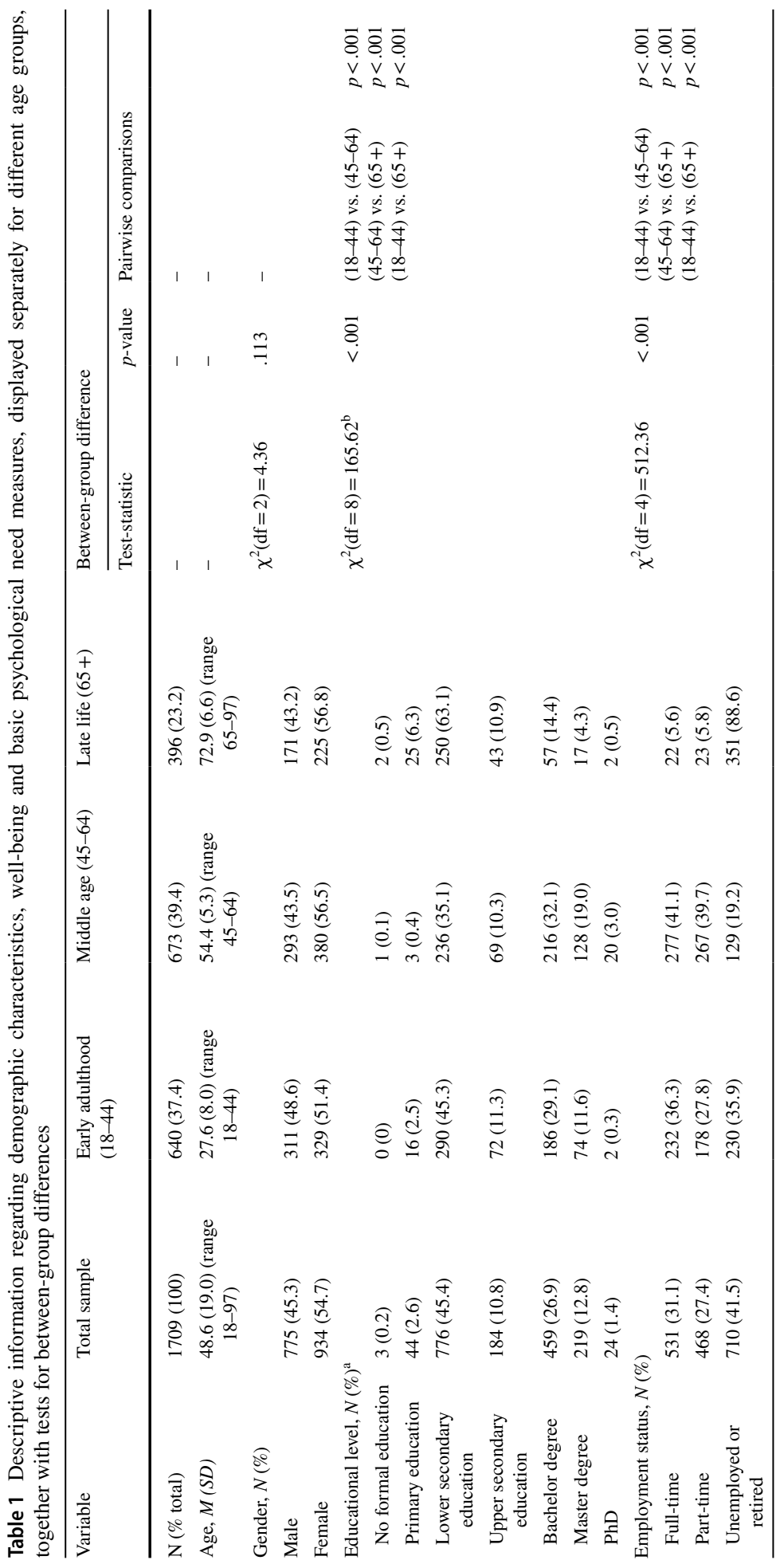




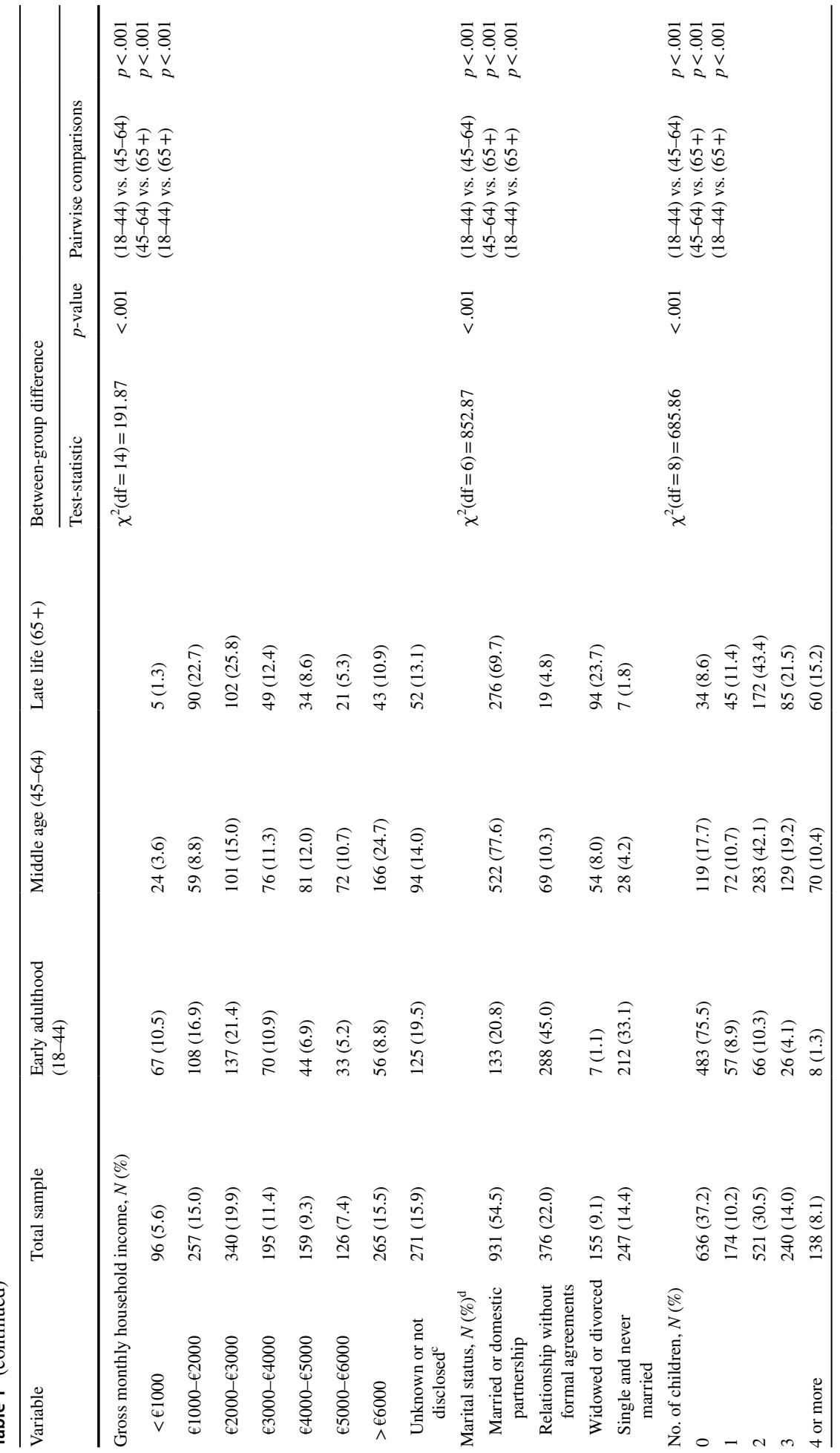




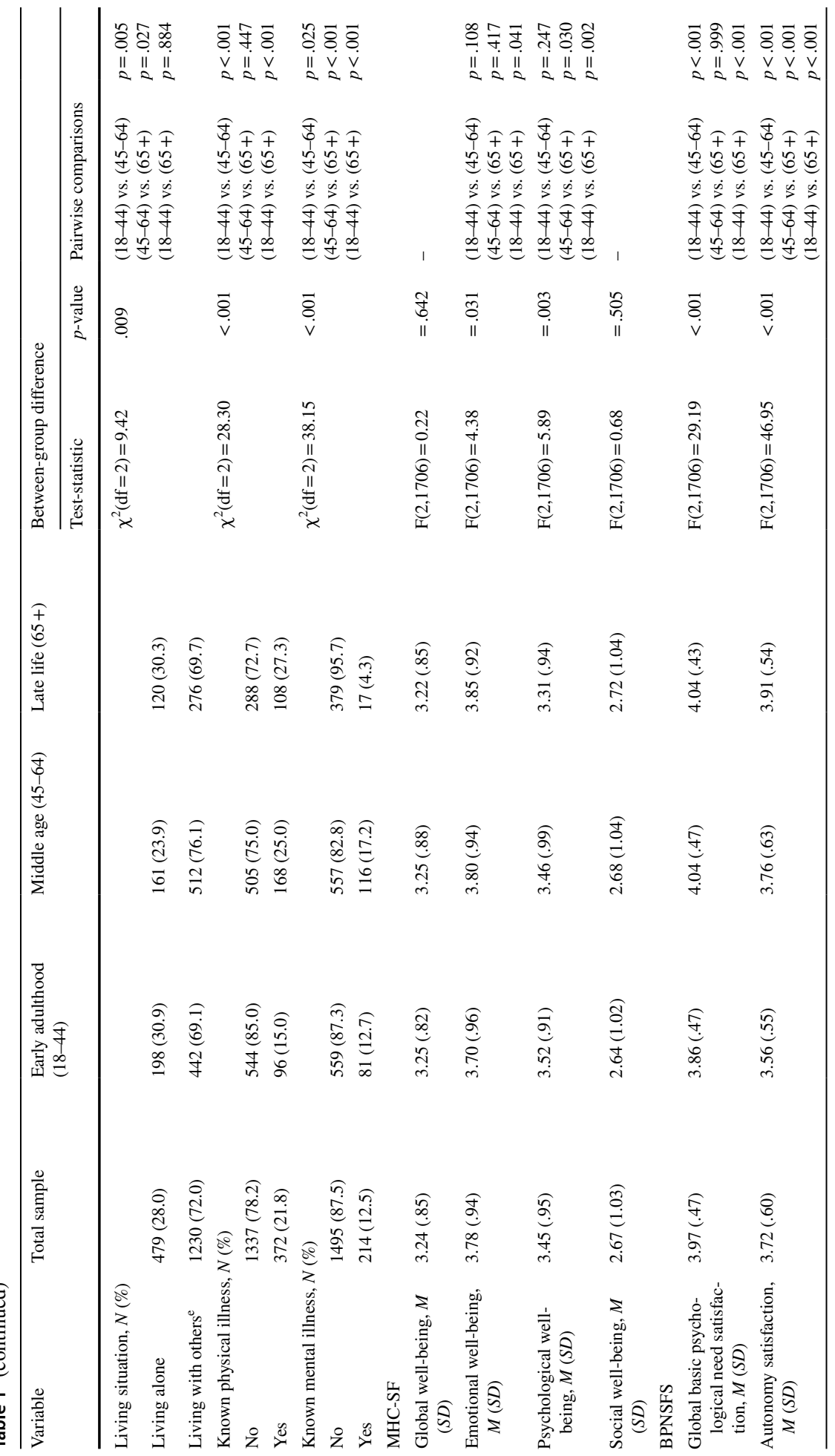




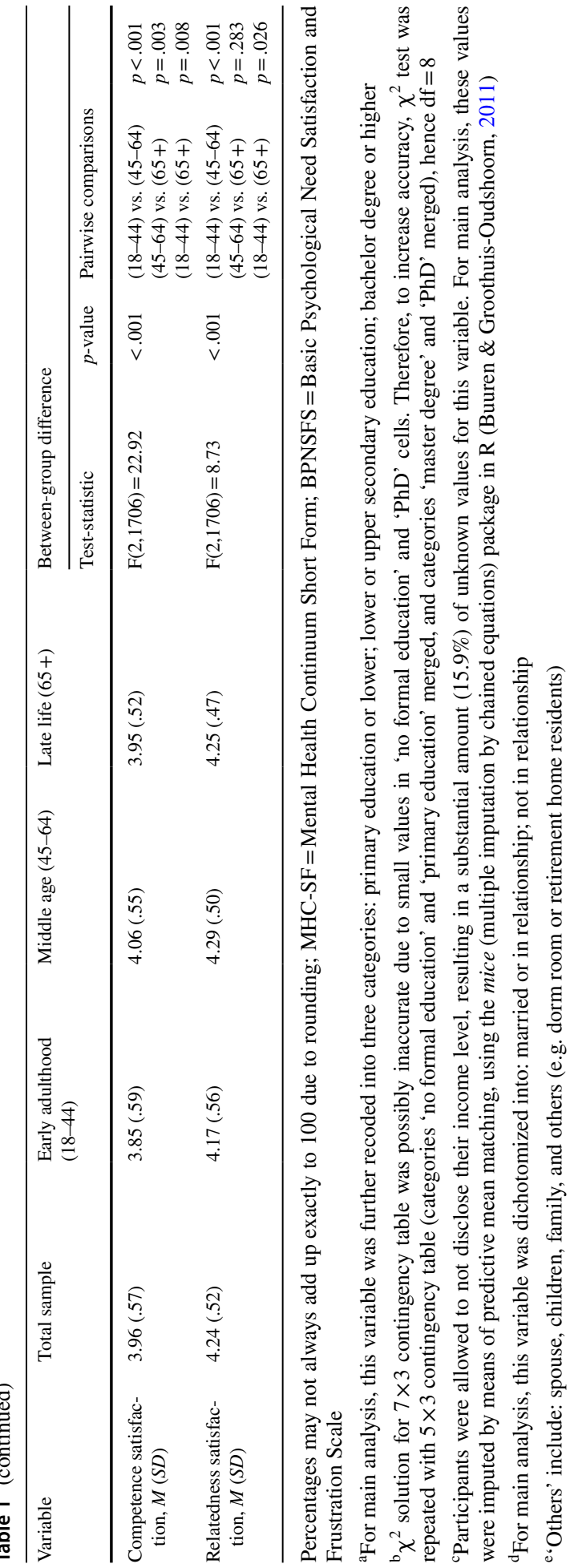


from 1 (not true at all) to 5 (completely true). Development and validation of the Dutch BPNSFS were previously described, demonstrating good internal reliability, convergent, and discriminant validity in a Dutch-speaking sample of university students (Chen et al., 2015), and no evidence of differential item functioning as a function of age (Tóth-Király et al., 2018). While confirmatory factor analysis has suggested superiority of a measurement model of the BPNSFS that distinguishes between satisfaction and frustration in each need domain (Chen et al., 2015), recently more sophisticated statistical evaluations have indicated need satisfaction and frustration, as measured by the BPNSFS, to more likely represent two endpoints of the same underlying continuum (Tóth-Király et al., 2018, 2019). This is further supported by the observation that need satisfaction and frustration tend to correlate strongly (Chen et al., 2015; Tóth-Király et al., 2018), and show associations with various correlates in completely opposite directions (Campbell et al., 2019; Chen et al., 2015; Costa et al., 2016; Schultz et al., 2015). For the sake of parsimony, we therefore decided to reverse code the negatively formulated ('frustration') items of the BPNSFS and incorporate them into composite need satisfaction scores, as was done in previous studies (Campbell et al., 2019; Chen et al., 2015). Thus, by doing so, higher scores are reasonably assumed to reflect higher levels of need satisfaction, provided that scale reliability is sufficient.

2.3.1.1 Global Basic Psychological Need Satisfaction The mean score on all twenty-four propositions of the BPNSFS was used as indicator of global basic psychological need satisfaction (for descriptive purposes only). Internal consistency of the total BPNSFS scale in the current sample was considered excellent: Cronbach's $\alpha=0.90$.

2.3.1.2 Autonomy Satisfaction The mean score on the eight propositions of the BPNSFS that pertain to the satisfaction of the need for autonomy (e.g., I feel a sense of choice and freedom in the things I undertake) was used as indicator of overall satisfaction of the need for autonomy. Internal consistency of the BPNSFS autonomy satisfaction subscale in the current sample was considered good: Cronbach's $\alpha=0.80$.

2.3.1.3 Competence Satisfaction The mean score on the eight BPNSFS propositions pertaining to the satisfaction of the need for competence (e.g., I feel I can successfully complete difficult tasks) was used as indicator of overall satisfaction of the need for competence. Internal consistency of the BPNSFS competence satisfaction subscale in the current sample was considered good: Cronbach's $\alpha=0.81$.

2.3.1.4 Relatedness Satisfaction The mean score on the eight propositions of the BPNSFS that pertain to the satisfaction of the need for relatedness (e.g., I feel close and connected with other people who are important to me) was used as indicator of overall satisfaction of the need for relatedness. Internal consistency of the BPNSFS relatedness satisfaction subscale in the current sample was considered good: Cronbach's $\alpha=0.81$.

\subsubsection{Mental Health Continuum Short Form}

The validated Dutch Mental Health Continuum Short Form (MHC-SF, Lamers et al., 2011) was used to assess global well-being, in addition to domain-specific well-being in the subdomains of emotional, psychological, and social well-being. The questionnaire consists of fourteen items in total, asking participants to reflect on well-being-related experiences 
during the past month (e.g., During the past month, how often did you feel satisfied with life?), using a six-point Likert-type scale: 1 (never); 2 (once or twice); 3 (about once a week); 4 (two or three times a week); 5 (almost every day), and; 6 (every day). Higher scores indicate higher levels of well-being. Previous studies in representative samples of Dutch-speaking participants have demonstrated high internal and moderate test-retest reliability of the Dutch MHC-SF, as well as good convergent and discriminant validity (Lamers et al., 2011), in addition to sufficient measurement invariance across demographic groups (Lamers et al., 2012).

2.3.2.1 Global Well-Being The mean score on all fourteen items of the MHC-SF was used as global well-being measure (for descriptive purposes only). Internal consistency of the total MHC-SF scale in the current sample was considered excellent: Cronbach's $\alpha=0.90$.

2.3.2.2 Emotional Well-Being The 'emotional well-being' subscale of the MHC-SF consists of three items (e.g., During the past month, how often did you feel happy?), assessing life satisfaction and positive feelings, and the mean score on these items was used as indicator of the overall level of emotional well-being during the past month. Internal consistency of the MHC-SF emotional well-being subscale in the current sample was considered good: Cronbach's $\alpha=0.85$.

2.3.2.3 Psychological Well-Being The mean score on the six items of the "psychological well-being' subscale of the MHC-SF (e.g., During the past month, how often did you feel that your life has a sense of direction or meaning to it?) was used to represent the overall level of psychological well-being during the past month, across the components self-acceptance, environmental control, positive relations, personal growth, autonomy, and purpose in life. Internal consistency of the MHC-SF psychological well-being subscale in the current sample was considered good: Cronbach's $\alpha=0.85$.

2.3.2.4 Social Well-Being The 'social well-being' subscale of the MHC-SF consists of five items (e.g., During the past month, how often did you feel that you belonged to a community (like a social group, or your neighborhood)?), assessing social contribution, integration, actualization, acceptance, and coherence, and the mean score on these items was used as indicator of the overall level of social well-being during the past month. Internal consistency of the MHC-SF social well-being subscale in the current sample was considered acceptable: Cronbach's $\alpha=0.76$.

\subsubsection{Demographic Factors}

In addition to the assessment of well-being and basic psychological need satisfaction, participants were asked to provide information on their age, gender, educational level (highest level completed), employment status, gross monthly household income, marital status, number of children, living situation, and known physical and mental illness(es) (see Table 1 for detailed demographic description of the sample). 


\subsection{Analyses}

All analyses were performed in $\mathrm{R}$ version 4.0.3 ( $\mathrm{R}$ Core Team, 2020). For descriptive purposes, and in order to explore demographic variability, and variability in global and domain-specific well-being and need satisfaction, the sample was divided into three age groups (early adulthood $(18-44$ years; $n=640)$, middle age ( $45-64$ years; $n=673$ ), and late life $(65+; n=396))$. ANOVA and $\chi^{2}$ tests were performed to assess differences between these groups, followed up by pairwise comparisons whenever yielding significant results (see Table 1).

\subsubsection{Distributions of Basic Psychological Need Satisfaction and Well-Being Across Age}

Initial inspection of the shape of the distributions of domain-specific need satisfaction and well-being across age was performed by applying locally estimated scatterplot smoothing (LOESS; detailed in Cleveland \& Devlin, 1988) to scatterplots of, respectively, autonomy, competence, and relatedness satisfaction, and emotional, psychological, and social wellbeing factors as a function of age as continuous factor (see Figs. 1a and 2a, respectively; plots created using ggplot2 package; Wickham, 2016). Non-linearity was subsequently tested by stepwise comparing the relative fit of three nested models with age as linear predictor (base model; step 1), and age entered additionally as quadratic $\left(\mathrm{age}^{2}\right.$ ), and cubic $\left(\mathrm{age}^{3}\right)$ predictors at steps 2 and 3, respectively. Relative fit of nested models was compared using $\chi^{2}$ difference tests. Continuous need satisfaction and well-being factors were standardized prior to model fitting, as was the continuous factor age, before creating squared $\left(\mathrm{age}^{2}\right)$ and cubed $\left(\mathrm{age}^{3}\right)$ transformations (Kim, 1999). All models included a priori identified covariates gender, educational level, gross monthly household income, marital / relationship status, living situation, number of children, employment status, known physical illness, and known mental illness (see also recommendations in: López Ulloa et al., 2013). Because participants were allowed to not disclose their gross monthly household income, a substantial amount (15.9\%) of values for this factor were missing (or rather: unknown). Excluding records for which these values were missing from analyses may have introduced bias (see e.g. Moore et al., 2000). Therefore, using the mice (multiple imputation by chained equations) package (Buuren \& Groothuis-Oudshoorn, 2011), missing income values were imputed by means of predictive mean matching, generating five imputed datasets. Reported model estimates (see Tables 2, 3, 4) thus represent pooled estimates from analyses across these datasets. Estimated adjusted relationships between age and, respectively, autonomy, competence, and relatedness satisfaction, and emotional, psychological, and social well-being factors were additionally plotted as line graphs (see Figs. $1 \mathrm{~b}$ and $2 \mathrm{~b}$ ).

\subsubsection{Associations Between Basic Psychological Need Satisfaction and Well-Being}

To test whether basic psychological need fulfillment was associated with well-being across all ages, the factors autonomy, competence, and relatedness satisfaction, and their interaction with age, were added in stepwise fashion as separate predictors to the multiple regression models best describing emotional, psychological, and social well-being (see Table 4). Significant interactions were followed up by stratified analyses, i.e., examination of the association of interest across different age strata. 


\section{Results}

\subsection{Demographic Variability}

Analyses of demographic variability across early adulthood (EA), middle age (MA), and late life (LL) age groups (see Table 1), suggested that the ratio male / female participants was similar across age groups, but revealed group differences for educational level (highest in MA, followed by EA and LL), retirement/unemployment rates (highest in LL, followed by EA and MA), gross monthly income (highest in MA, followed by LL and EA), marital status (MA/LL more often married than EA; EA more often single or in relationship without formal agreements than MA/LL), number of children (higher in MA/LL, compared to EA), known physical illness (less common in EA, compared to MA/LL), and known mental illness (most common in MA, followed by EA and LL).

\subsection{Distributions of Well-Being and Need Satisfaction Across Age}

See Figs. 1a and 2a. Apart from autonomy satisfaction, for which a linear relationship with age was suggested, visual inspection of loess smoothed curves suggested non-linearity of relationships between age and need satisfaction and, respectively, well-being factors.

See Table 2. Results from model fitting best supported a linear relationship between age and autonomy satisfaction (see Fig. 1b), confirming interpretation from initial visual inspection of the data. Model fit for autonomy satisfaction did not increase with inclusion of quadratic $\left(\chi_{\text {diff }}^{2}(1)=3.01, p=0.083, \Delta \mathrm{R}^{2}=0.1 \%\right)$ nor cubic age terms $\left(\chi_{\text {diff }}^{2}(1)=0.11\right.$, $\left.\mathrm{p}=0.737, \Delta \mathrm{R}^{2}=-0.1 \%\right)$. Although initial visual inspection suggested an inverted $\mathrm{U}$-shaped relationship between age and competence satisfaction, inclusion of a quadratic age term did not improve model fit $\left(\chi_{\text {diff }}^{2}(1)=2.24, p=0.136, \Delta R^{2}=0.1 \%\right)$, and none of the tested models supported a relationship between age and competence satisfaction when taking into account variability in other demographic factors (see Fig. 1b). For the criterion

(a)

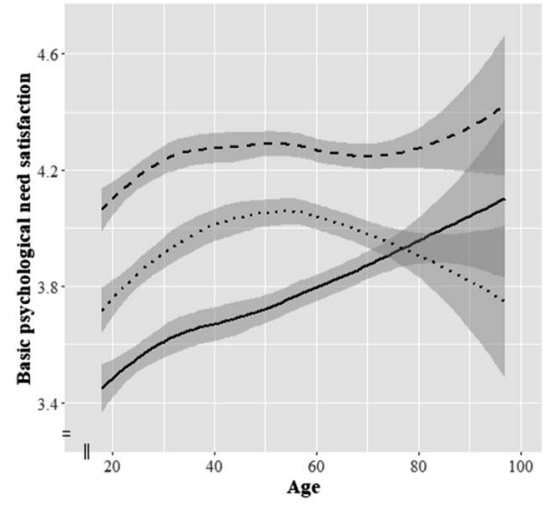

(b)

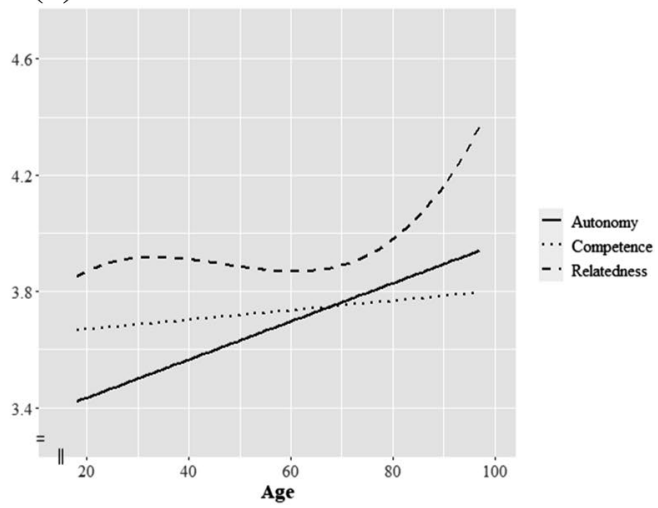

Fig. 1 Relationship between age and satisfaction of the need for autonomy (solid line), competence (dotted line), and relatedness (dashed line): a unadjusted relationship, based on scatterplot; grey-shaded bands around LOESS smoothed curves represent 95\% confidence intervals for fitted values; b estimated relationship, adjusted for gender, educational level, employment, income, relationship status, living situation, number of children, physical illness, and mental illness 
(a)

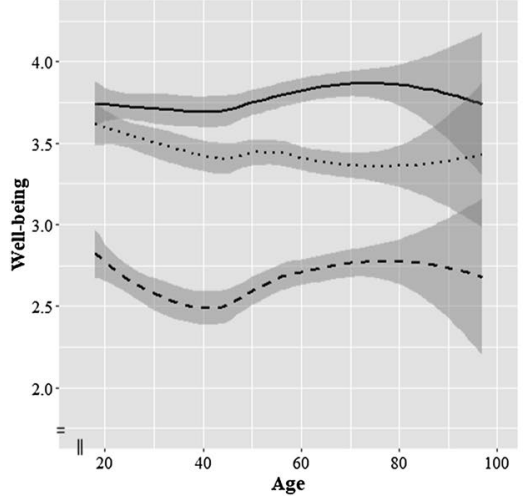

(b)

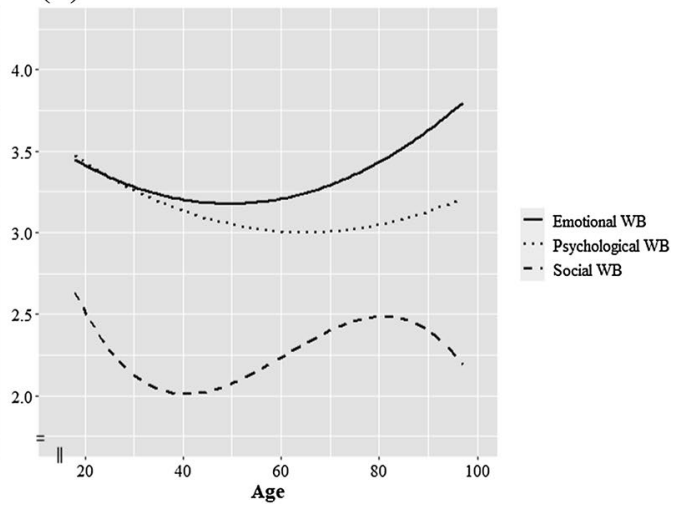

Fig. 2 Relationship between age and emotional (solid line), psychological (dotted line), and social wellbeing (dashed line): a unadjusted relationship, based on scatterplot; grey-shaded bands around LOESS smoothed curves represent $95 \%$ confidence intervals for fitted values; $\mathbf{b}$ estimated relationship, adjusted for gender, educational level, employment, income, relationship status, living situation, number of children, physical illness, and mental illness

variable relatedness satisfaction, data best supported a slight positive cubic (S-shaped) relationship with age $\left(\chi_{\text {diff }}^{2}(1)=5.79, \mathrm{p}=0.017, \Delta \mathrm{R}^{2}=0.3 \%\right)$, with 'turning points' estimated at 33.39 (local maximum) and 60.67 years (local minimum; corrected for other demographic factors, see Fig. 1b).

See Table 3. Model fit for the criterion variables emotional and psychological wellbeing improved slightly but significantly with inclusion of a quadratic age term (respectively, $\chi_{\text {diff }}^{2}(1)=11.85, p<0.001, \Delta \mathrm{R}^{2}=0.6 \%$, and $\left.\chi_{\text {diff }}^{2}(1)=6.96, p=0.008, \Delta \mathrm{R}^{2}=0.3 \%\right)$, whereas additional inclusion of a cubic age term further improved model fit slightly but significantly for social well-being $\left(\chi_{\text {diff }}^{2}(1)=12.67, \mathrm{p}<0.001, \Delta \mathrm{R}^{2}=0.7 \%\right)$. Data thus best supported slight $\mathrm{U}$-shaped relations between age and both emotional and psychological well-being, with nadirs estimated at respectively 49.48 and 65.24 years (corrected for other demographic factors, see Fig. 2b, resp.), and a slight negative cubic (S-shaped) relationship between age and social well-being, with 'turning points' estimated at 40.65 (local minimum) and 80.85 years (local maximum; corrected for other demographic factors, see Fig. 2b).

\subsection{Associations Between Basic Psychological Need Satisfaction and Well-Being}

See Table 4. Autonomy, competence, and relatedness satisfaction were significantly associated with emotional, psychological, and social well-being, and together explained a substantial added proportion of variance in all well-being factors on top of the variance explained by demographic variables alone.

Model fit for the criterion variables emotional and psychological well-being did not improve significantly by adding interactions of autonomy, competence, and relatedness satisfaction $\times$ age as predictors to the model (respectively, $\chi_{\text {diff }}^{2}(6)=1.24, p=0.282$, $\Delta \mathrm{R}^{2}=0.1 \%$, and $\left.\chi_{\text {diff }}^{2}(6)=1.76, \mathrm{p}=0.103, \Delta \mathrm{R}^{2}=0.2 \%\right)$, in line with the universality assumption.

Model fit for the criterion variable social well-being improved slightly but significantly when adding interactions of autonomy, competence, and relatedness satisfaction $\times$ age as 


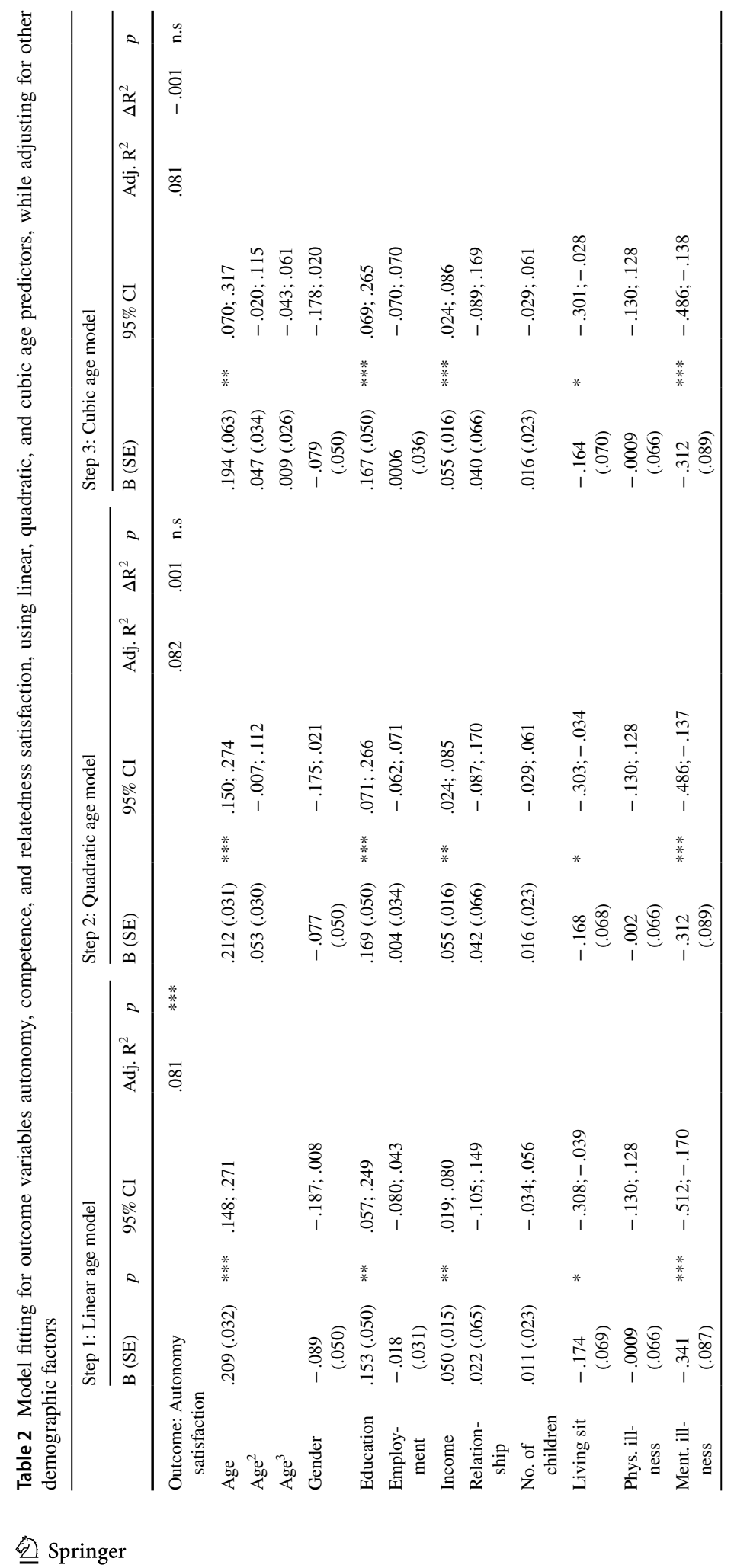




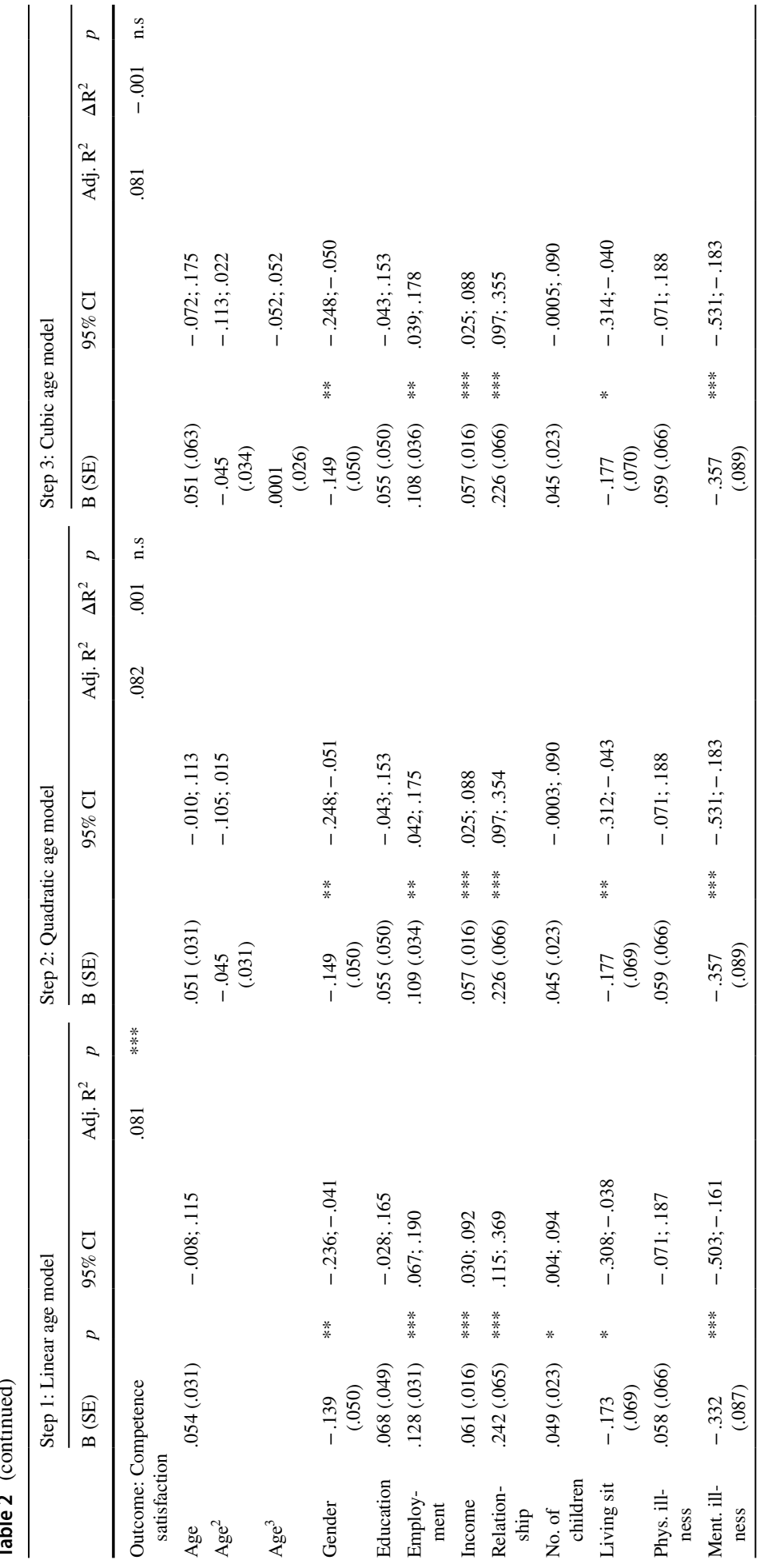




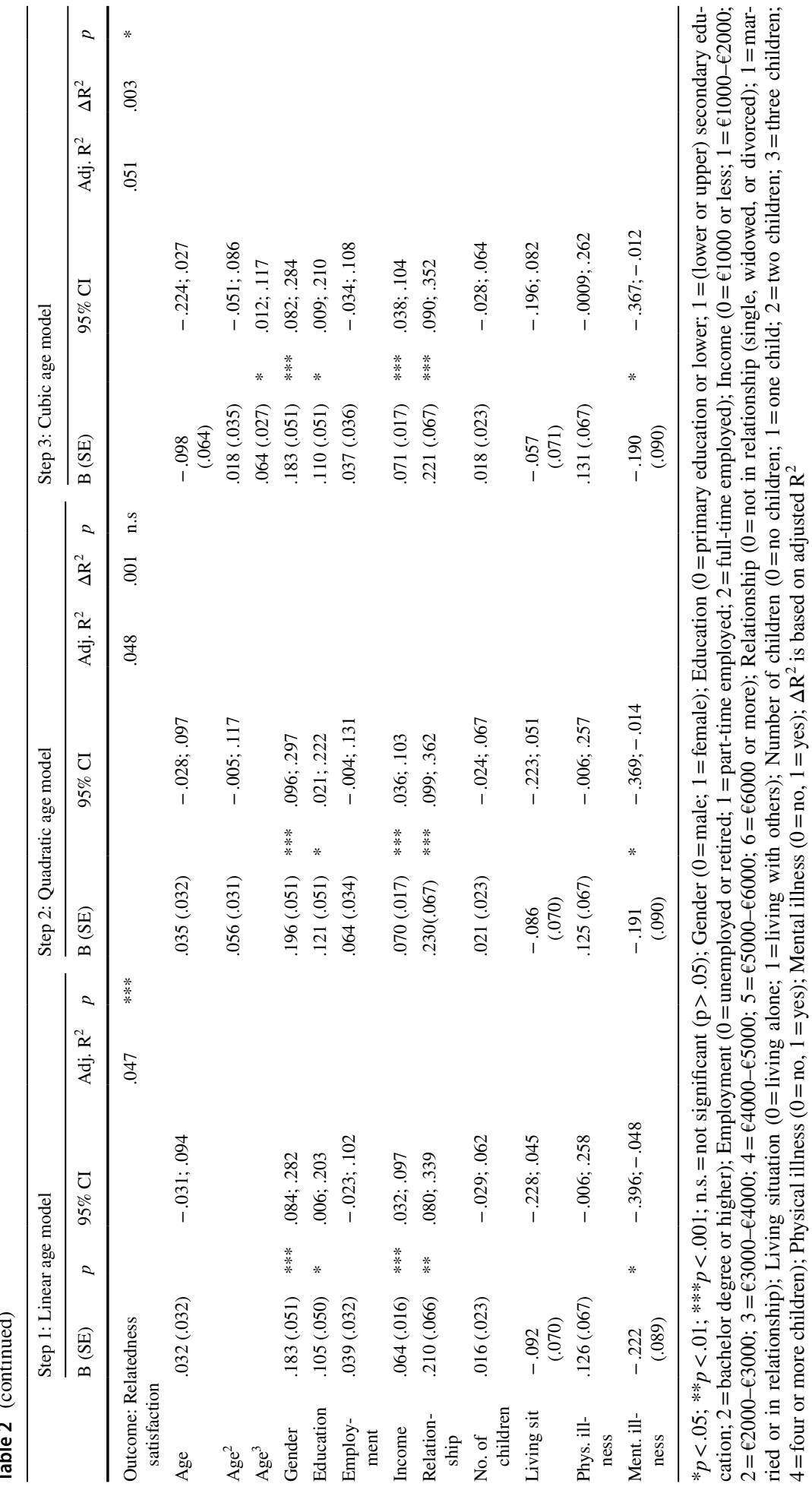


predictors to the model $\left(\chi_{\text {diff }}^{2}(9)=2.32, p=0.013, \Delta \mathrm{R}^{2}=0.6 \%\right)$ : the association between relatedness satisfaction and social well-being was suggested to be partly age-dependent (see Table 4). Stratified analyses indicated that relatedness was positively and most strongly associated with social well-being in the late life age stratum $(B(S E)=0.153, p=0.021)$, followed by the early adulthood stratum $(B(S E)=0.089(0.04), p=0.037)$, whereas no significant relationship between relatedness and social well-being was found in the middle age stratum $(\mathrm{B}(\mathrm{SE})=0.051, \mathrm{p}=0.260)$.

\section{Discussion}

This cross-sectional study aimed to (i) more closely examine the age distribution of satisfaction of the three separate basic psychological needs, and (ii) investigate whether satisfaction of each of the three basic psychological needs was comparably associated with well-being across all ages, as predicted by the universality assumption of basic psychological need satisfaction, while taking into account variability in demographic correlates of basic psychological need satisfaction and/or well-being.

\subsection{Age Distributions of Emotional, Psychological, and Social Well-Being}

Our analysis identified distinct age distributions for different components of well-being. For emotional well-being, findings best supported a slight U-shaped distribution, with an estimated 'dip' around age fifty, and highest levels of emotional well-being for adults in late life, as generally reported previously (Baird et al., 2010; Blanchflower \& Oswald, 2008; Cheng et al., 2017; Clark, 2007; Clark \& Oswald, 2006; Frijters \& Beatton, 2012; Jiang et al., 2012; Le Bon \& Le Bon, 2014; Stone et al., 2010; Van Landeghem, 2008, 2012). Although psychological well-being was also best described as slightly convex across age, the nadir in our sample was estimated around age 65, i.e., at considerably later age than in previous studies, and the overall distribution appeared to slope slightly downward. Previous studies have yielded rather mixed results on the distribution of psychological well-being across age (Lamers et al., 2012; Morgan \& Robinson, 2013; Ryff, 1989), most likely due to considerable variety in the choice of indicators for psychological wellbeing, an issue which is further addressed below. Social well-being, lastly, was suggested to follow a slight negative cubic distribution across age, with a 'dip' for adults around age forty, and relatively higher levels of social well-being for older adults, with a 'peak' around age eighty - a pattern previously described for global life satisfaction in the British Household Panel and German Socio-Economic Panel Studies (Baird et al., 2010; Gwozdz $\&$ Sousa-Poza, 2010). In addition, social well-being was overall lower than both emotional and psychological well-being, in line with previous studies employing the MHC-SF (Lamers et al., 2011, 2012).

Despite differences in distributions of emotional, psychological, and social well-being across age, our data are supportive of an overall decline in well-being from adolescence into midlife, with a tendency to steadily increase thereafter, although possibly dropping sharply for some aspects of well-being in very old age. This rather consistent finding has been previously discussed in the context of several potential explanations. The 'burden of midlife' hypothesis, i.e. the suggestion that the midlife nadir in well-being is attributable purely to life circumstances, is not strongly supported by our findings, given the quadratic and cubic age terms remained significant predictors of well-being, also when correcting 


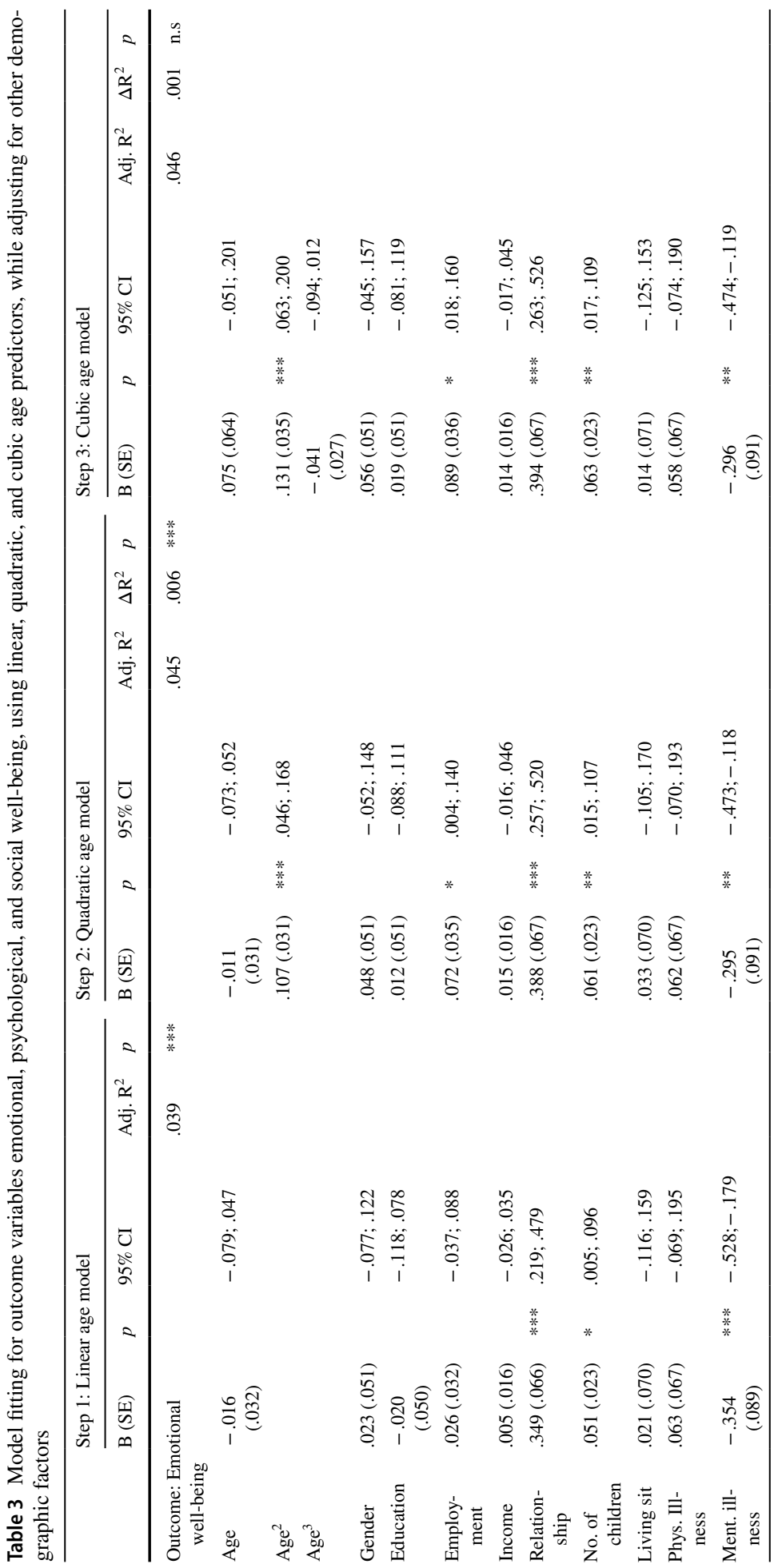




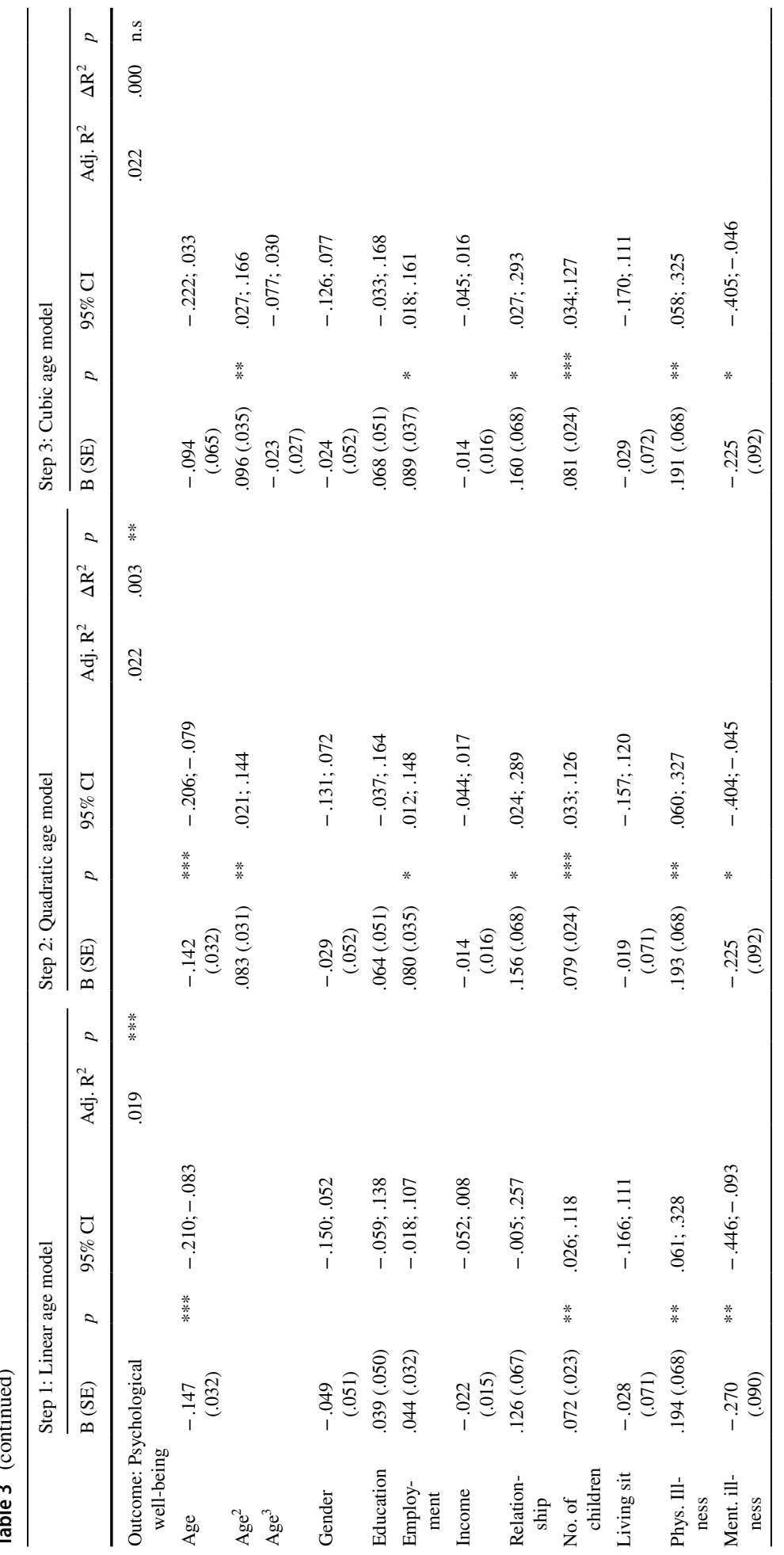




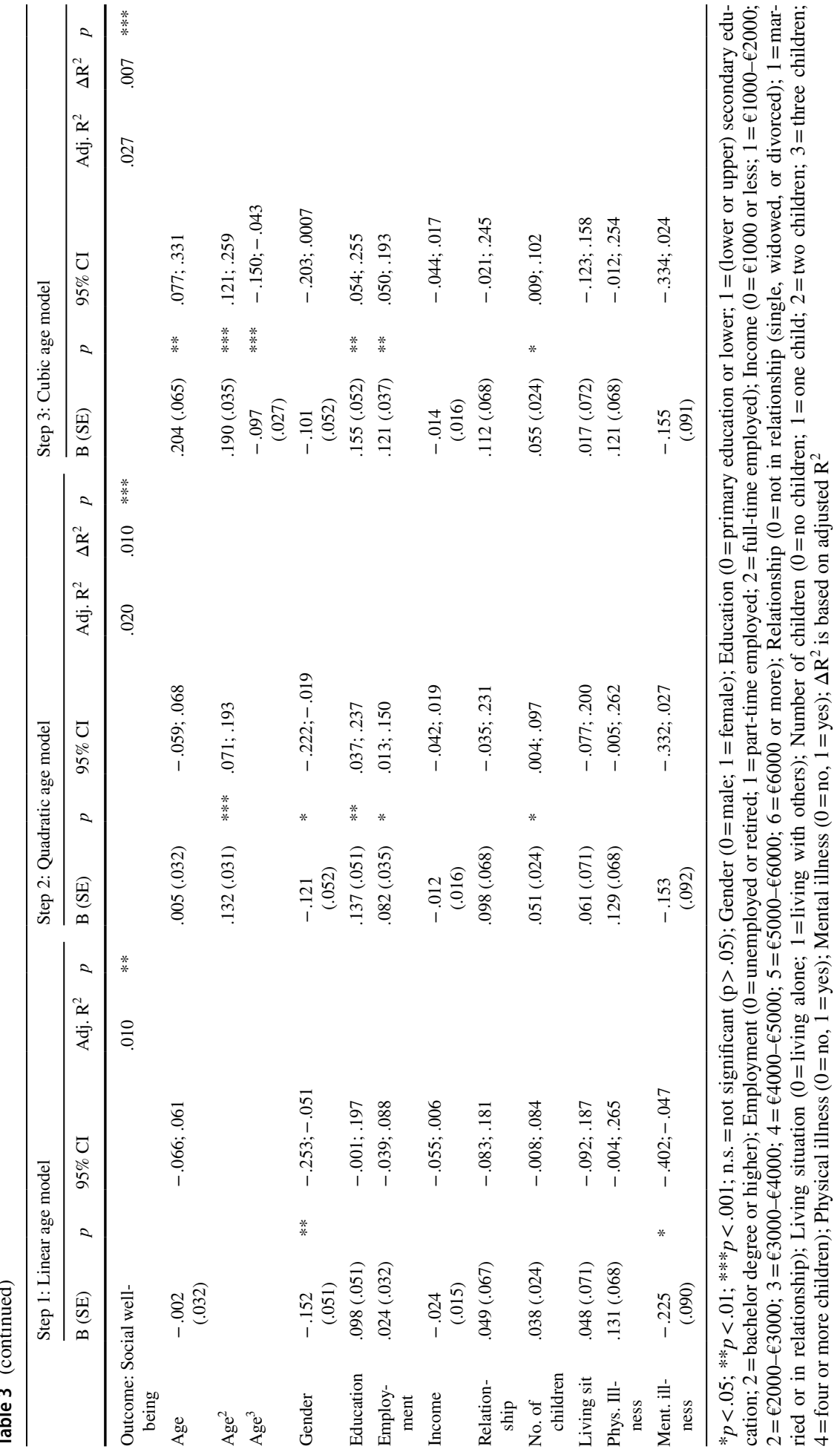


for other demographic factors. However, the hypothesis can neither be discarded based on our data, because we did not include direct measures of midlife phenomena associated with well-being, such as the experience of multiple role demands, financial pressures, and lack of leisure time (Lachman et al., 2015). Nonetheless, our findings seem to align with those from previous studies (e.g., Diener et al., 2018; Myers \& Diener, 1996), suggesting that the midlife 'dip' in well-being across age does not merely reflect the impact of external circumstances. Alternatively, differences in well-being across the lifespan have been ascribed to a number of psychological processes related to aging. Most notably, socioemotional selectivity theory (Carstensen, 1992; Carstensen et al., 1999) suggests that, with increasing age, human attention shifts towards more present-oriented and positive emotion-related goals, and the social environment is systematically and increasingly shaped in pursuit of these. This (self-)regulatory mechanism, which is also central to e.g. action theory (Brandtstadter, 1999), may result in higher levels of, especially, emotional and social well-being in late life, in line with current observations. In addition, as further endorsed by gerotranscendence theory (Tornstam, 1997), an increased emphasis on appreciating and enjoying the present moment and social interactions in late life, may shift attention away from more future-oriented and self-centered goals and achievements, with possible implications for psychological aspects of well-being pertaining thereto. Contemporary developmental theories thus seem to provide converging ideas regarding the psychological mechanisms that may underlie age-related differences in well-being, as observed in the current dataset. Despite the notion that levels of well-being in late life tend to remain relatively high and resilient to age-related threats, such as social losses and declining health, there is evidence that additional mortality-related burdens and dysfunctions in very old age may eventually lead to a (sharp) decline in well-being (e.g., Gerstorf et al., 2008, 2010, 2018), and our data tend to partially support this. A third category of explanations for differences in well-being across age focus on methodological study aspects (e.g., design, sampling), which are discussed more generally in the limitations section of this paper.

\subsection{Age Distributions of Autonomy, Competence, and Relatedness Satisfaction}

Distinct age distributions were also observed for different basic psychological need components. In line with recent findings among Hungarian adults (Tóth-Király et al., 2018), we found evidence of a linear increase in autonomy satisfaction with age. Although visual inspection suggested an inverted U-shaped relationship between age and competence satisfaction, this relationship was fully accounted for by other demographic factors, most notably, having a job, a relatively high income, being in a relationship, and living together. The suggested 'midlife peak' in competence satisfaction, as previously reported by Tóth-Király et al. (2018), was thus likely explained by the fact that middle aged adults in our sample more commonly endorsed these characteristics, rather than representing a 'pure' age effect. Also, whereas Tóth-Király et al. (2018) did not find a significant relationship between age and relatedness fulfillment, our data supported a slight positive cubic relationship, with a 'peak' for adults in early adulthood, slightly lower levels for adults around 60 years of age, and again higher levels of relatedness fulfillment for those at the upper end of the age range.

The observation that increasing age was associated with higher levels of autonomy satisfaction fits previously mentioned developmental theories (e.g. socioemotional selectivity theory, action theory; Brandtstadter, 1999; Carstensen, 1992), which describe an age-related increase in the regulation (i.e., selection or modification) of 


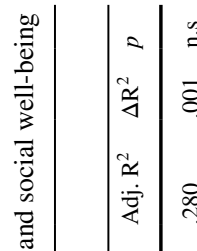

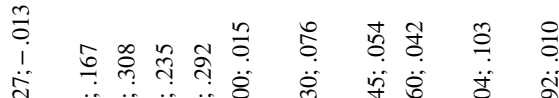

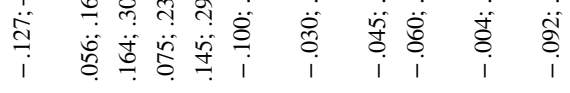

帘

* $\quad * * * * * * *$

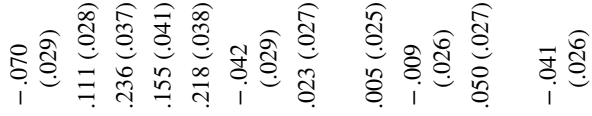

$\mid=2$

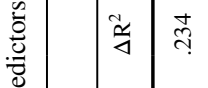

$\int_{0} \underset{\frac{1}{2}}{\approx}$

空

$\frac{1}{6}$

i.

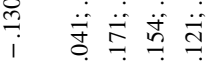

* * * * * * *

童

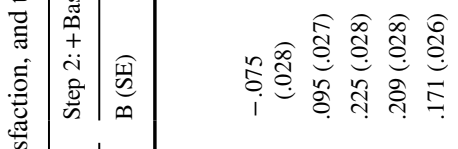

$=$

总

苞 ${ }^{\square}$

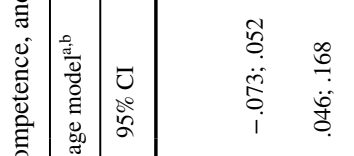

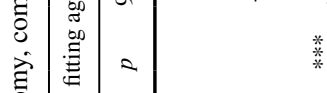

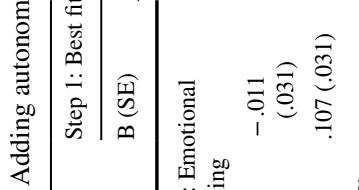

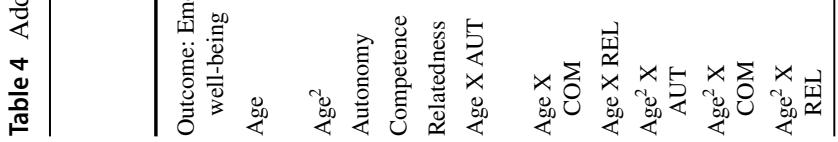

Springer 


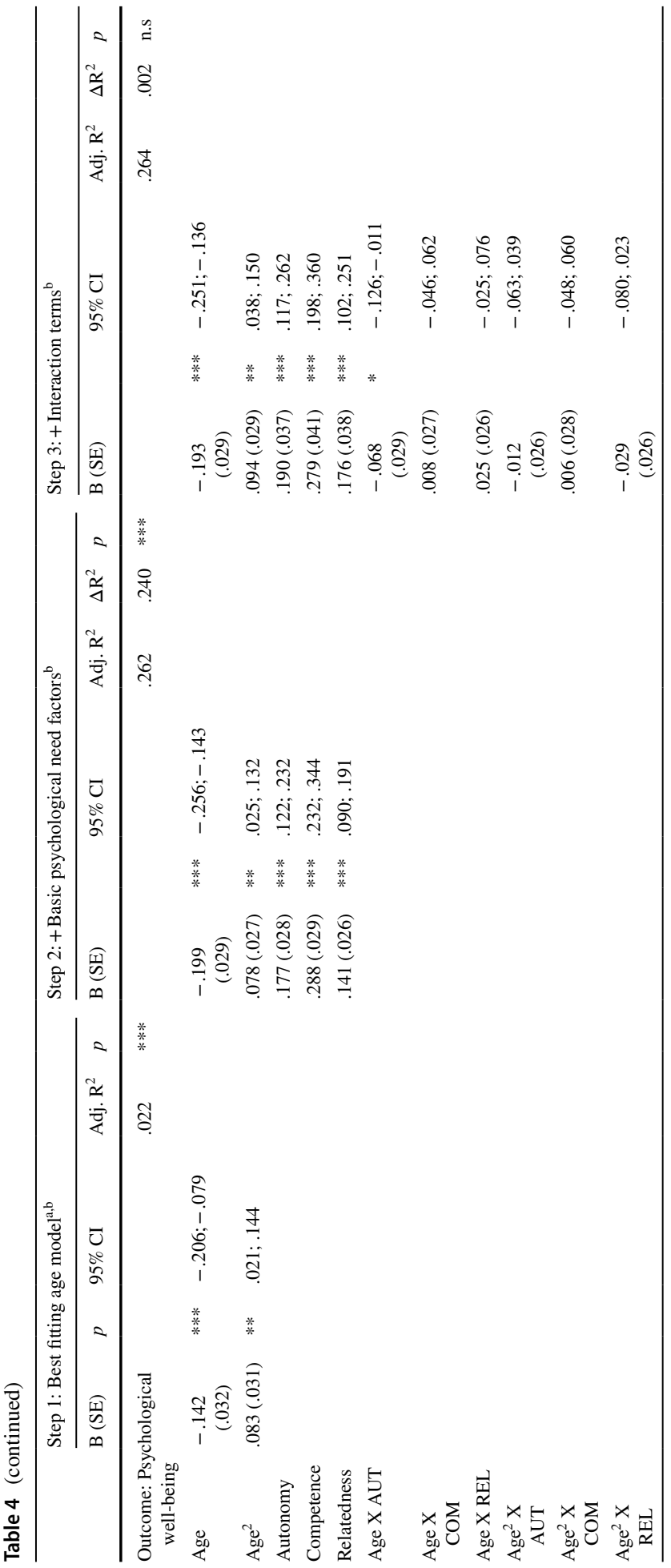




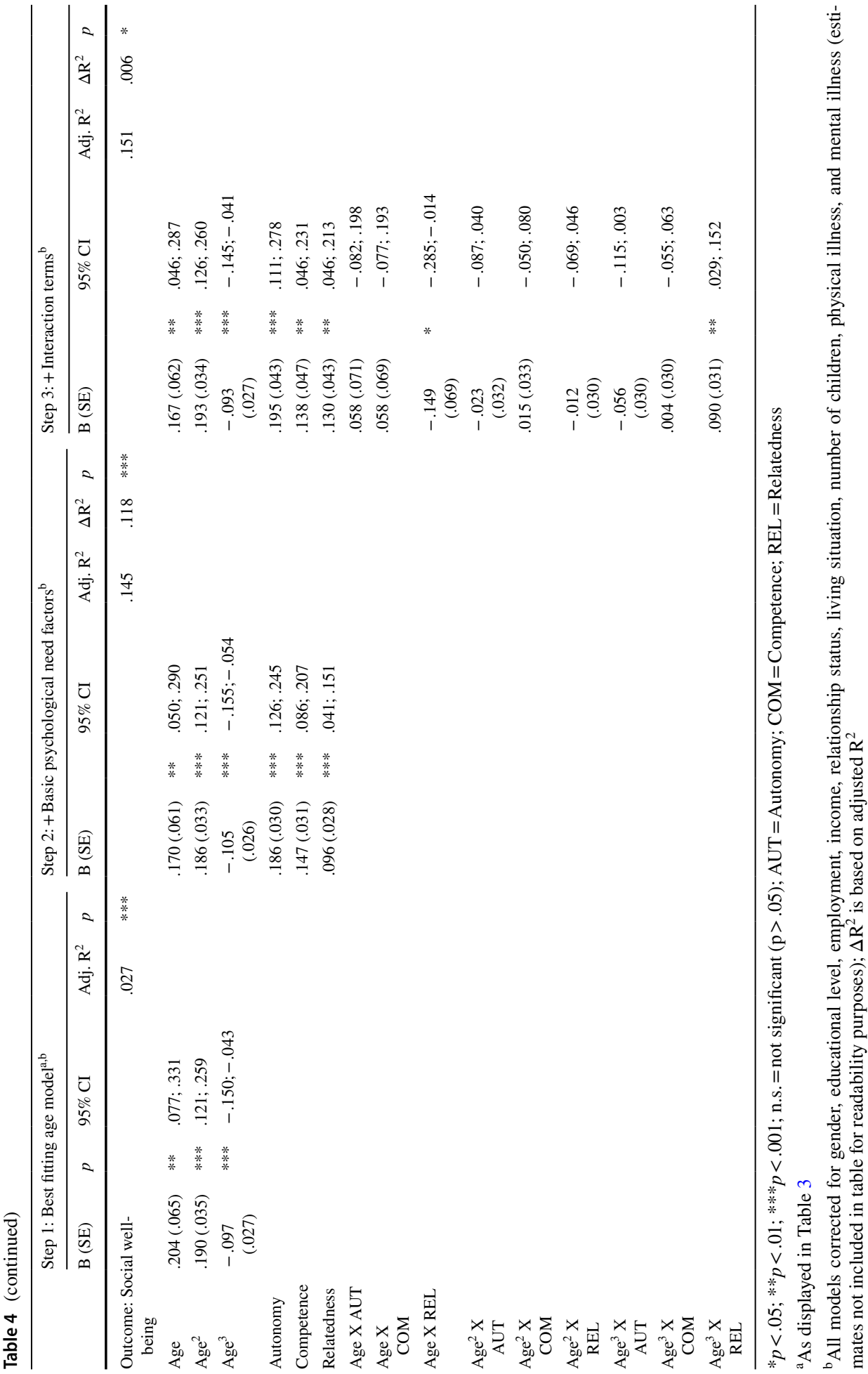


(social) environments in line with personal needs. In addition, old age may be naturally accompanied by a reduction in social obligations and pressures (e.g., work, family) that may threaten autonomy fulfillment (Tóth-Király et al., 2018). Our findings regarding the age distribution of competence satisfaction are in line with the idea of midlife as a period of social maturity (Caspi et al., 2005; Roberts \& Wood, 2015), i.e., a period providing optimal opportunities to become a productive and involved contributor to society. Middle aged adults in our sample were most likely to engage in active work and family roles, and these indicators of societal involvement were associated with increased competence satisfaction. In addition, previous work has highlighted increased levels of environmental mastery in midlife (Ryff, 1989), i.e. individuals in midlife tend to feel more 'in control' of their life, and better equipped to deal with the challenges accompanying it, which may be expressed partly through higher scores on competence satisfaction. The slight 'dip' in relatedness satisfaction on the brink of old age may reflect the impact of role loss due to retirement, widowhood, and reduced social connections, typically occurring during this life phase (Elwell \& Maltbie-Crannell, 1981; Nicolaisen \& Thorsen, 2017; Singh \& Misra, 2009). However, in line with socioemotional selectivity theory and findings on social well-being, the distribution of relatedness across age generally supports the notion of sustained or increased satisfaction with the quality of social relationships throughout the lifespan, despite age-related threats thereto (Antonucci \& Akiyama, 1995; Carstensen, 1992; Luong et al., 2011).

It should also be noted that variance in all outcomes appeared to be considerably larger at later ages (see Figs. 1a; 2a), which is most likely explained by the relatively small number of participants in our sample at the upper end of the age range (i.e., 80-89 years: $n=66$, and $\geq 90$ years: $n=7$ ). An alternative, although more speculative explanation for this observation could be that there is genuinely more heterogeneity in basic psychological need satisfaction and well-being scores among relatively older adults, which may be worth further investigation as it may point to heterogeneity in the aging processes underlying these measures.

\subsection{Relationship Between Basic Psychological Needs Fulfillment and Well-Being}

As predicted from self-determination theory (Deci \& Ryan, 2008; Ryan \& Deci, 2000), all basic psychological need components were positively and significantly associated with well-being in all domains, and together explained a more substantial proportion of variance therein (up to 24\%), than did demographic factors (no more than 5\%). In general, our data did not hint towards systematic age-specific associations between basic psychological need satisfaction and well-being, thus overall supporting the notion that fulfillment of basic psychological needs is indeed comparably linked to well-being across age, in line with the universality assumption. Only with regard to the positive relationship between relatedness and social well-being, our data may indicate that this association is partly age-dependent, as it appeared most evident in late life. Although generally in line with the idea of social relationships being particularly important for maintaining health and well-being in late life (Antonucci \& Akiyama, 1995; Carstensen, 1992; Choi, et al., 2018), replication is warranted, considering the possibility of this finding reflecting a Type I error (discussed below). 


\subsection{Strengths and Limitations}

Although the current study has a number of strengths-most notably the domain-specific rather than global assessment of basic psychological need satisfaction and wellbeing, attention to confounding factors, and the large and demographically diverse sample-findings should be interpreted in light of several limitations.

First, due to the cross-sectional nature of the study, we cannot exclude the possibility that age-associated patterns in our data reflect historically influenced cohort differences, rather than developmental change across the lifespan, and no conclusions can be drawn regarding the causality of relationships. Although previous work suggests that cohort effects cannot (fully) explain well-being differences across age groups (see e.g., Blanchflower \& Oswald, 2008; Clark, 2007), longitudinal assessment is required, in combination with specific analysis techniques (see e.g., Van Landeghem, 2012), to isolate the relative contributions of historical and developmental factors to age-associated findings. Second, although data collection was aimed at collecting a representative sample, recruitment procedures may have led to underrepresentation of certain demographic groups, such as socially isolated or hospitalized individuals, thereby potentially biasing results (see also: S. R. Lucas, 2014 for potential limitations of non-probability sampling). Third, although the use of self-report questionnaires is justifiable in the context of our research questions, this method of assessment is linked to a number of well-described response biases (see e.g., Paulhus \& Vazire, 2007), of which some may be associated with age (e.g., Soubelet \& Salthouse, 2011). Therefore, although considered unlikely, we cannot rule out the possibility that our results are systematically confounded by self-report bias. Fourth, whereas most developmental theories highlight the importance of the proximal social environment (Brandtstadter, 1999; Carstensen, 1992; Garbarino, 1980; Tornstam, 1997), our measure of social well-being represented the degree of satisfaction with more distal and possibly more abstract social relations at the community and societal level, and findings should be interpreted with this in mind. Fifth, although statistically significant, the actual relevance of observed age effects is subject to debate (see e.g., Blanchflower \& Oswald, 2008; López Ulloa et al., 2013), and with a large enough sample, even trivial differences may become statistically significant (Jacobs et al., 2013). However, in our sample, the variation in well-being across age was estimated to be around half a standard deviation, and that of basic psychological need satisfaction a full standard deviation, indicative of medium to large effects (Cohen, 1988). Indeed, previous work has suggested that the magnitude of the age effect on well-being is comparable to that of major life events, and therefore substantial and meaningful (Blanchflower \& Oswald, 2008). Sixth, considering the number of models that were tested, some significant findings may represent a Type I error in the context of multiple testing. This may be particularly relevant for the models in which a large number of interaction terms were introduced (Table 4), and the significant interaction between relatedness and age in the model of social well-being should therefore be interpreted with caution. Seventh, although covariate selection was based on empirical arguments, some demographic covariates may have been redundant, and it should be recognized that parsimonious (i.e., 'simpler') models with relatively fewer covariates tend to have more prediction accuracy when applied to new data contexts (Vandekerckhove et al., 2015). Lastly, missing income values were imputed, based on the assumption that excluding records for which these values were missing would have introduced bias (see e.g., Moore et al., 2000). However, imputation may not necessarily produce more 
accurate results (Sterne et al., 2009). Therefore, as advised by Jakobson et al. (2017), sensitivity analyses were performed using listwise deletion to deal with missing data, which yielded similar conclusions.

\section{Conclusion}

The present study is among the first to systematically examine age distributions of satisfaction of the three separate basic psychological needs-autonomy, competence, and relatedness-, while taking into account variability in other demographic correlates of basic psychological need satisfaction. Distinct age distributions were found and described for different components of basic psychological need satisfaction and well-being. Specifically, when correcting for other demographic factors, we found a positive linear relationship between age and autonomy satisfaction, no significant relationship between age and competence satisfaction, and a slight positive cubic relationship between age and relatedness satisfaction. Moreover, all basic psychological need factors were generally found to be strongly associated with well-being in all domains and across all ages, lending support to the universality assumption of self-determination theory. Taken together, these findings further increase the understanding of age-associated differences in human experience in a variety of domains, and support the idea that, despite distinct age distributions, all three basic psychological needs remain important for maintaining a sense of well-being throughout life.

Acknowledgements We are very grateful to Carina van Berlo-Rooijakkers, Martha Bijlholt, Daniëla Dorhout Mees, Pieter Houtekamer, Pepijn van der Hulle, Thea Jansman, Saskia Kuling, Timen Llurba-Jaspers, Robin van de Maat, Silvie Otter, Ams Slemmer, Karin van Sluyters van Nimwegen, Hans Smulders, and Greet Vandenberk for contributing to the data collection for this study.

Authors' Contributions All authors contributed to the study conception and design. Material preparation, data collection and analysis were performed by Johan Lataster and Jennifer Reijnders. The first draft of the manuscript was written by Johan Lataster and Jennifer Reijnders, and all authors commented on previous versions of the manuscript. All authors read and approved the final manuscript.

Funding No funds, grants, or other financial support was received for conducting this study.

Data Availability The data that support the findings of this study are available from the corresponding author, Johan Lataster, upon reasonable request.

Code Availability Not applicable.

\section{Declarations}

Ethical Approval The study was approved by the local research ethics committee of the Open University of The Netherlands, and was carried out in accordance with APA Ethical Standards (American Psychological Association, 2002) regarding research with human participants.

Informed Consent Participation in the study was voluntary and anonymous, and all participants gave informed consent to participate, after being fully informed about the study and having had the opportunity to have any questions answered.

Conflict of interest The authors have no conflicts of interest to declare that are relevant to the content of this article. 
Open Access This article is licensed under a Creative Commons Attribution 4.0 International License, which permits use, sharing, adaptation, distribution and reproduction in any medium or format, as long as you give appropriate credit to the original author(s) and the source, provide a link to the Creative Commons licence, and indicate if changes were made. The images or other third party material in this article are included in the article's Creative Commons licence, unless indicated otherwise in a credit line to the material. If material is not included in the article's Creative Commons licence and your intended use is not permitted by statutory regulation or exceeds the permitted use, you will need to obtain permission directly from the copyright holder. To view a copy of this licence, visit http://creativecommons.org/licenses/by/4.0/.

\section{References}

American Psychological Association. (2002). Ethical principles of psychologists and code of conduct. American Psychologist, 57, 1060-1073.

Andrews, F. M., \& Withey, S. B. (2012). Social indicators of well-being: Americans' perceptions of life quality. Springer.

Antonucci, T., \& Akiyama, H. (1995). Convoys of social relations: Family and friendships within a life span context. Handbook of Aging and the Family.

Baird, B. M., Lucas, R. E., \& Donnellan, M. B. (2010). Life Satisfaction across the lifespan: Findings from two nationally representative panel studies. Social Indicators Research, 99(2), 183-203. https://doi.org/10.1007/s11205-010-9584-9

Baltes, P. B. (1987). Theoretical propositions of life-span developmental psychology: On the dynamics between growth and decline. Developmental Psychology, 23(5), 611-626. https://doi.org/10.1037/ 0012-1649.23.5.611

Beard, J. R., Officer, A., Carvalho, I. A., Sadana, R., Pot, A. M., Michel, J.-P., Lloyd-Sherlock, P., Epping-Jordan, J.-A.E., Peeters, G. M. E. E., Mahanani, W. R., Thiyagarajan, J. A., \& Chatterji, S. (2016). The World report on ageing and health: a policy framework for healthy ageing. The Lancet, 387(10033), 2145-2154. https://doi.org/10.1016/S0140-6736(15)00516-4

Blanchflower, D. G., \& Graham, C. L. (2020). The Mid-Life Dip in Well-Being: Economists (Who Find It) Versus Psychologists (Who Don't)! (NBER Working Paper No. w26888). National Bureau of Economic Research. https://www.nber.org/system/files/working_papers/w26888/w26888.pdf

Blanchflower, D. G., \& Oswald, A. J. (2004). Well-being over time in Britain and the USA. Journal of Public Economics, 88(7-8), 1359-1386.

Blanchflower, D. G., \& Oswald, A. J. (2008). Is well-being U-shaped over the life cycle? Social Science \& Medicine, 66(8), 1733-1749. https://doi.org/10.1016/j.socscimed.2008.01.030

Brandtstadter, J. (1999). Sources of resilience in the aging self: Toward integrating perspectives. In T. M. Hess \& F. Blanchard-Fields (Eds.), Social cognition and aging (pp. 123-141). Elsevier.

Campbell, A., Converse, P. E., \& Rodgers, W. L. (1976). The quality of American life: Perceptions, evaluations, and satisfactions. Russell Sage Foundation.

Campbell, R., Vansteenkiste, M., Delesie, L., Soenens, B., Tobback, E., Vogelaers, D., \& Mariman, A. (2019). The role of basic psychological need satisfaction, sleep, and mindfulness in the healthrelated quality of life of people living with HIV. Journal of Health Psychology, 24(4), 535-545.

Carstensen, L. L. (1992). Motivation for social contact across the life span: a theory of socioemotional selectivity. Nebraska Symposium on Motivation.

Carstensen, L. L., Isaacowitz, D. M., \& Charles, S. T. (1999). Taking time seriously: A theory of socioemotional selectivity. American Psychologist, 54(3), 165-181. https://doi.org/10.1037/0003066X.54.3.165

Caspi, A., Roberts, B. W., \& Shiner, R. L. (2005). Personality development: Stability and change. Annual Review of Psychology, 56(1), 453-484. https://doi.org/10.1146/annurev.psych.55.090902. 141913

Chen, B., Vansteenkiste, M., Beyers, W., Boone, L., Deci, E. L., Van der Kaap-Deeder, J., Duriez, B., Lens, W., Matos, L., Mouratidis, A., Ryan, R. M., Sheldon, K. M., Soenens, B., Van Petegem, S., \& Verstuyf, J. (2015). Basic psychological need satisfaction, need frustration, and need strength across four cultures. Motivation and Emotion, 39(2), 216-236. https://doi.org/10.1007/s11031-014-9450-1

Cheng, T. C., Powdthavee, N., \& Oswald, A. J. (2017). Longitudinal evidence for a midlife nadir in human well-being: Results from four data sets. The Economic Journal, 127(599), 126-142. https://doi.org/10. 1111/ecoj. 12256 
Choi, E., Kwon, Y., Lee, M., Choi, J., \& Choi, I. (2018). Social relatedness and physical health are more strongly related in older than younger adults: Findings from the Korean Adult Longitudinal Study. Frontiers in Psychology, 9, 3.

Clark, A., \& Oswald, A. (2006). The curved relationship between subjective well-being and age. Halshs$00590404 f, 1-12$.

Clark, A. (2007). Born to be mild? Cohort effects don't (fully) explain why well-being is $U$ shaped in age. IZA discussion paper no. 3170, 1-29.

Cleveland, W. S., \& Devlin, S. J. (1988). Locally weighted regression: An approach to regression analysis by local fitting. Journal of the American Statistical Association, 83(403), 596-610.

Cohen, J. (1988). Statistical power analysis for the behavioral sciences. Routledge.

Costa, S., Gugliandolo, M. C., Barberis, N., \& Larcan, R. (2016). The mediational role of psychological basic needs in the relation between conception of god and psychological outcomes. Journal of Religion and Health, 55(1), 1-15.

Crawford Solberg, E., Diener, E., Wirtz, D., Lucas, R. E., \& Oishi, S. (2002). Wanting, having, and satisfaction: Examining the role of desire discrepancies in satisfaction with income. Journal of Personality and Social Psychology, 83(3), 725-734. https://doi.org/10.1037/0022-3514.83.3.725

Cummins, R. A. (1996). The domains of life satisfaction: An attempt to order chaos. Social Indicators Research, 38(3), 303-328. https://doi.org/10.1007/BF00292050

de Leeuw, E. D. (2005). To mix or not to mix data collection modes in surveys. Journal of Official Statistics, 21(2), 233-255.

Deci, E. L., \& Ryan, R. M. (2000). The "what" and "why" of goal pursuits: Human needs and the self-determination of behavior. Psychological Inquiry, 11(4), 227-268. https://doi.org/10.1207/S15327965P LI1104_01

Deci, E. L., \& Ryan, R. M. (2008). Self-determination theory: A macrotheory of human motivation, development, and health. Canadian Psychology/psychologie Canadienne, 49(3), 182-185. https://doi.org/ $10.1037 / \mathrm{a} 0012801$

Deci, E. L., \& Vansteenkiste, M. (2004). Self-determination theory and basic need satisfaction: Understanding human development in positive psychology. Ricerche Di Psicologia, 27(1), 23-40.

Demir, M., \& Davidson, I. (2013). Toward a better understanding of the relationship between friendship and happiness: Perceived responses to capitalization attempts, feelings of mattering, and satisfaction of basic psychological needs in same-sex best friendships as predictors of happiness. Journal of Happiness Studies, 14(2), 525-550.

Di Domenico, S. I., \& Fournier, M. A. (2014). Socioeconomic status, income inequality, and health complaints: A basic psychological needs perspective. Social Indicators Research, 119(3), 1679-1697. https://doi.org/10.1007/s11205-013-0572-8

Diener, E., Oishi, S., \& Tay, L. (2018). Advances in subjective well-being research. Nature Human Behaviour, 2(4), 253-260. https://doi.org/10.1038/s41562-018-0307-6

Dolan, P., Peasgood, T., \& White, M. (2008). Do we really know what makes us happy? A review of the economic literature on the factors associated with subjective well-being. Journal of Economic Psychology, 29(1), 94-122.

Easterlin, R. A. (2010). Happiness, growth, and the life cycle. In H. Hinte \& K. F. Zimmermann (Eds.). New York: Oxford University Press.

Easterlin, R. A. (2006). Life cycle happiness and its sources. Journal of Economic Psychology, 27(4), 463482. https://doi.org/10.1016/j.joep.2006.05.002

Elwell, F., \& Maltbie-Crannell, A. D. (1981). The impact of role loss upon coping resources and life satisfaction of the elderly. Journal of Gerontology, 36(2), 223-232. https://doi.org/10.1093/geronj/ 36.2.223

Ferrand, C., Martinent, G., \& Durmaz, N. (2014). Psychological need satisfaction and well-being in adults aged 80years and older living in residential homes: Using a self-determination theory perspective. Journal of Aging Studies, 30, 104-111. https://doi.org/10.1016/j.jaging.2014.04.004

Freund, A. M. (2017). Motivational changes across adulthood: The role of goal representations for adult development and aging. In R. A. Scott, \& M. Buchmann (Eds.), Emerging trends in the behavioral and social sciences (2017), https://doi.org/10.1002/9781118900772.etrds0424

Frey, B. S., \& Stutzer, A. (2002). Happiness and economics: How the economy and institutions affect well-being. Princeton University Press.

Frijters, P., \& Beatton, T. (2012). The mystery of the U-shaped relationship between happiness and age. Journal of Economic Behavior \& Organization, 82(2-3), 525-542. https://doi.org/10.1016/j.jebo. 2012.03.008 
Fry, P. S., \& Keyes, C. L. M. (2010). New Frontiers in Resilient Aging. In P. S. Fry \& C. L. M. Keyes (Eds.), New frontiers in resilient aging: Life-strengths and well-being in late life. https://doi.org/10. 1017/CBO9780511763151

Garbarino, J. (1980). The ecology of human development: Experiments by nature and design. Children and Youth Services Review, 2(4), 433-438. https://doi.org/10.1016/0190-7409(80)90036-5

Gerstorf, D., Hülür, G., Wagner, G. G., Kunzmann, U., \& Ram, N. (2018). Terminal change across facets of affective experience and domain satisfaction: Commonalities, differences, and bittersweet emotions at the end of life. Developmental Psychology, 54(12), 2382-2402. https://doi.org/10.1037/ dev0000599

Gerstorf, D., Ram, N., Estabrook, R., Schupp, J., Wagner, G. G., \& Lindenberger, U. (2008). Life satisfaction shows terminal decline in old age: Longitudinal evidence from the German Socio-Economic Panel Study (SOEP). Developmental Psychology, 44(4), 1148-1159. https://doi.org/10.1037/00121649.44.4.1148

Gerstorf, D., Ram, N., Mayraz, G., Hidajat, M., Lindenberger, U., Wagner, G. G., \& Schupp, J. (2010). Late-life decline in well-being across adulthood in Germany, the United Kingdom, and the United States: Something is seriously wrong at the end of life. Psychology and Aging, 25(2), 477-485. https://doi.org/10.1037/a0017543

Gröpel, P., \& Kuhl, J. (2009). Work-life balance and subjective well-being: The mediating role of need fulfilment. British Journal of Psychology, 100(2), 365-375. https://doi.org/10.1348/000712608X337797

Grover, S., \& Helliwell, J. F. (2019). How's life at home? New evidence on marriage and the set point for happiness. Journal of Happiness Studies, 20(2), 373-390.

Gwozdz, W., \& Sousa-Poza, A. (2010). Ageing, health and life satisfaction of the oldest old: An analysis for Germany. Social Indicators Research, 97(3), 397-417. https://doi.org/10.1007/s11205-009-9508-8

Hahn, J., \& Oishi, S. (2006). Psychological needs and emotional well-being in older and younger Koreans and Americans. Personality and Individual Differences, 40(4), 689-698.

Henning, G., Bjälkebring, P., Stenling, A., Thorvaldsson, V., Johansson, B., \& Lindwall, M. (2019). Changes in within-and between-person associations between basic psychological need satisfaction and well-being after retirement. Journal of Research in Personality, 79, 151-160.

Huber, M., Knottnerus, J. A., Green, L., Horst, H. V. D., Jadad, A. R., Kromhout, D., \& Smid, H. (2011). How should we define health? BMJ, 343(2), d4163. https://doi.org/10.1136/bmj.d4163

Jacobs, R., Murphy, K., \& Silva, J. (2013). Unintended consequences of EEO enforcement policies: Being big is worse than being bad. Journal of Business and Psychology, 28(4), 467-471. https:// doi.org/10.1007/s10869-012-9268-3

Jiang, S., Lu, M., \& Sato, H. (2012). Identity, inequality, and happiness: Evidence from urban China. World Development, 40(6), 1190-1200. https://doi.org/10.1016/j.worlddev.2011.11.002

Keyes, C. L. M. (2014). Mental health as a complete state: How the salutogenic perspective completes the picture. Bridging occupational, organizational and public health. https://doi.org/10.1007/ 978-94-007-5640-3

Kim, D.-S. (1999). A standardization technique to reduce the problem of multicollinearity in polynomial regression analysis. Retrieved from http://www.stat.fi/isi99/proceedings/arkisto/varasto/kim_0574.pdf

Lachman, M. E., Teshale, S., \& Agrigoroaei, S. (2015). Midlife as a pivotal period in the life course: Balancing growth and decline at the crossroads of youth and old age. International Journal of Behavioral Development, 39(1), 20-31.

Lamers, S. M. A., Glas, C. A. W., Westerhof, G. J., \& Bohlmeijer, E. T. (2012). Longitudinal evaluation of the mental health continuum-short form (MHC-SF). European Journal of Psychological Assessment, 28(4), 290-296. https://doi.org/10.1027/1015-5759/a000109

Lamers, S. M. A., Westerhof, G. J., Bohlmeijer, E. T., ten Klooster, P. M., \& Keyes, C. L. M. (2011). Evaluating the psychometric properties of the mental health Continuum-Short Form (MHC-SF). Journal of Clinical Psychology, 67(1), 99-110. https://doi.org/10.1002/jclp.20741

Le Bon, O., \& Le Bon, S.-D. (2014). Age distribution curve in psychiatric admissions inversely correlates with Life Satisfaction. Psychiatry Research, 219(1), 232-234. https://doi.org/10.1016/j.psychres.2014. 05.001

López Ulloa, B. F., Møller, V., \& Sousa-Poza, A. (2013). How does subjective well-being evolve with age? A literature review. Journal of Population Ageing, 6(3), 227-246. https://doi.org/10.1007/ s12062-013-9085-0

Lucas, R. E., \& Diener, E. (2000). Personality and subjective well-being across the life span. In V. J. Molfese \& D. L. Molfese (Eds.), Temperament and personality development across the life span (pp. 211-234). Lawrence Erlbaum Associates Publishers.

Lucas, S. R. (2014). An inconvenient dataset: Bias and inappropriate inference with the multilevel model. Quality \& Quantity, 48(3), 1619-1649. https://doi.org/10.1007/s11135-013-9865-x 
Luong, G., Charles, S. T., \& Fingerman, K. L. (2011). Better with age: Social relationships across adulthood. Journal of Social and Personal Relationships, 28(1), 9-23. https://doi.org/10.1177/0265407510 391362

Mackenzie, C. S., Karaoylas, E. C., \& Starzyk, K. B. (2018). Lifespan differences in a self determination theory model of eudaimonia: A cross-sectional survey of younger, middle-aged, and older adults. Journal of Happiness Studies, 19(8), 2465-2487.

McMahon, S. R., Iwamoto, M., Massoudi, M. S., Yusuf, H. R., Stevenson, J. M., David, F., Chu, S. Y., \& Pickering, L. R. (2003). Comparison of e-mail, fax, and postal surveys of pediatricians. Pediatrics, 111(4.1), 299-303.

Moore, J. C., Stinson, L. L., \& Welniak, E. J. (2000). Income Measurement error in surveys: A review. Journal of Official Statistics, 16(4), 331-361.

Morgan, J., \& Robinson, O. (2013). Intrinsic aspirations and personal meaning across adulthood: Conceptual interrelations and age/sex differences. Developmental Psychology, 49(5), 999-1010. https:// doi.org/10.1037/a0029237

Morgan, J., Robinson, O., \& Thompson, T. (2015). Happiness and age in European adults: The moderating role of gross domestic product per capita. Psychology and Aging, 30(3), 544-551. https://doi. org/10.1037/pag0000034

Myers, D. G., \& Diener, E. (1996). The pursuit of happiness. Scientific American, 54-56.

Nelson, S. K., Kushlev, K., \& Lyubomirsky, S. (2014). The pains and pleasures of parenting: When, why, and how is parenthood associated with more or less well-being? Psychological Bulletin, 140(3), 846-895. https://doi.org/10.1037/a0035444

Neubauer, A. B., Lerche, V., \& Voss, A. (2018). Interindividual differences in the intraindividual association of competence and well-being: Combining experimental and intensive longitudinal designs. Journal of Personality, 86(4), 698-713.

Ng, J. Y., Ntoumanis, N., Thøgersen-Ntoumani, C., Deci, E. L., Ryan, R. M., Duda, J. L., \& Williams, G. C. (2012). Self-determination theory applied to health contexts: A meta-analysis. Perspectives on Psychological Science, 7(4), 325-340.

Nicolaisen, M., \& Thorsen, K. (2017). What are friends for? Friendships and loneliness over the lifespan-From 18 to 79 years. The International Journal of Aging and Human Development, 84(2), 126-158. https://doi.org/10.1177/0091415016655166

Paulhus, D., \& Vazire, S. (2007). The self-report method. In R. W. Robins, R. C. Fraley, \& R. F. Krueger (Eds.), Handbook of research methods in personality psychology (pp. 224-239). The Guilford Press.

Petrillo, G., Capone, V., Caso, D., \& Keyes, C. L. (2015). The mental health continuum-short form (MHC$\mathrm{SF})$ as a measure of well-being in the Italian context. Social Indicators Research, 121(1), 291-312.

R Core Team. (2020). R: A language and environment for statistical computing. R Foundation for Statistical Computing, Vienna, Austria. https://www.R-project.org/

Roberts, B. W., \& Wood, D. (2015). Personality development in the context of the neo-socioanalytic model of personality. In Handbook of personality development. https://doi.org/10.4324/9781315805610.ch2

Ryan, R. M., \& Deci, E. L. (2000). Self-determination theory and the facilitation of intrinsic motivation, social development, and well-being. American Psychologist, 55(1), 68-78. https://doi.org/10.1037/ 0003-066X.55.1.68

Ryan, R. M., Bernstein, J. H., \& Brown, K. W. (2010). Weekends, work, and well-being: Psychological need satisfactions and day of the week effects on mood, vitality, and physical symptoms. Journal of Social and Clinical Psychology, 29(1), 95-122.

Ryan, R. M., Deci, E. L., \& Grolnick, W. S. (1995). Autonomy, relatedness, and the self: Their relation to development and psychopathology. In D. Cicchetti \& D. J. Cohen (Eds.), Wiley series on personality processes. Developmental psychopathology, Vol. 1. Theory and methods (pp. 618-655). Wiley.

Ryff, C. D. (1989). Happiness is everything, or is it? Explorations on the meaning of psychological wellbeing. Journal of Personality and Social Psychology, 57(6), 1069-1081. https://doi.org/10.1037/ 0022-3514.57.6.1069

Schultz, P. P., Ryan, R. M., Niemiec, C. P., Legate, N., \& Williams, G. C. (2015). Mindfulness, work climate, and psychological need satisfaction in employee well-being. Mindfulness, 6(5), 971-985.

Singh, A., \& Misra, N. (2009). Loneliness, depression and sociability in old age. Industrial Psychiatry Journal, 18(1), 51. https://doi.org/10.4103/0972-6748.57861

Soubelet, A., \& Salthouse, T. A. (2011). Influence of social desirability on age differences in self-reports of mood and personality. Journal of Personality, 79(4), 741-762. https://doi.org/10.1111/j.1467-6494. 2011.00700.x 
Sterne, J. A. C., White, I. R., Carlin, J. B., Spratt, M., Royston, P., Kenward, M. G., Wood, A. M., \& Carpenter, J. R. (2009). Multiple imputation for missing data in epidemiological and clinical research: Potential and pitfalls. BMJ, 338(1), b2393-b2393. https://doi.org/10.1136/bmj.b2393

Stone, A. A., Schwartz, J. E., Broderick, J. E., \& Deaton, A. (2010). A snapshot of the age distribution of psychological well-being in the United States. Proceedings of the National Academy of Sciences, 107(22), 9985-9990. https://doi.org/10.1073/pnas.1003744107

Tian, L., Chen, H., \& Huebner, E. S. (2014). The longitudinal relationships between basic psychological needs satisfaction at school and school-related subjective well-being in adolescents. Social Indicators Research, 119(1), 353-372.

Tornstam, L. (1997). Gerotranscendence: The contemplative dimension of aging. Journal of Aging Studies, 11(2), 143-154. https://doi.org/10.1016/S0890-4065(97)90018-9

Tóth-Király, I., Bőthe, B., Orosz, G., \& Rigó, A. (2019). A new look on the representation and criterion validity of need fulfillment: Application of the bifactor exploratory structural equation modeling framework. Journal of Happiness Studies, 20(5), 1609-1626.

Tóth-Király, I., Morin, A. J. S., Bőthe, B., Orosz, G., \& Rigó, A. (2018). Investigating the multidimensionality of need fulfillment: A bifactor exploratory structural equation modeling representation. Structural Equation Modeling: A Multidisciplinary Journal, 25(2), 267-286. https://doi.org/10.1080/10705511. 2017.1374867

Van Assche, J., van der Kaap-Deeder, J., Audenaert, E., De Schryver, M., \& Vansteenkiste, M. (2018). Are the benefits of autonomy satisfaction and the costs of autonomy frustration dependent on individuals' autonomy strength? Journal of Personality, 86(6), 1017-1036.

van Buuren, S., \& Groothuis-Oudshoorn, K. (2011). mice: Multivariate imputation by chained equations in R. Journal of Statistical Software, 45(3), 1-68. https://doi.org/10.18637/jss.v045.i03

Van Landeghem, B. (2008). Human well-being over the life cycle: Longitudinal evidence from a 20-year panel. SSRN Electronic Journal. https://doi.org/10.2139/ssrn.1360731

Van Landeghem, B. (2012). A test for the convexity of human well-being over the life cycle: Longitudinal evidence from a 20-year panel. Journal of Economic Behavior \& Organization, 81(2), 571-582. https://doi.org/10.1016/j.jebo.2011.08.001

Vandekerckhove, J., Matzke, D., \& Wagenmakers, E.-J. (2015). Model comparison and the principle of parsimony. In J. R. Busemeyer, Z. Wang, J. T. Townsend, \& A. Eidels (Eds.), The Oxford handbook of computational and mathematical psychology (pp. 300-319). Oxford University Press.

Vanhove-Meriaux, C., Martinent, G., \& Ferrand, C. (2018). Profiles of needs satisfaction and thwarting in older people living at home: Relationships with well-being and ill-being indicators. Geriatrics \& Gerontology International, 18, 470-478. https://doi.org/10.1111/ggi.13205

Veenhoven, R. (1991). Is happiness relative? Social Indicators Research, 24(1), 1-34. https://doi.org/10. 1007/BF00292648

Wickham, H. (2016). ggplot2-Elegant graphics for data analysis. Springer.

Zechmann, A., \& Paul, K. I. (2019). Why do individuals suffer during unemployment? Analyzing the role of deprived psychological needs in a six-wave longitudinal study. Journal of Occupational Health Psychology, 24(6), 641.

Publisher's Note Springer Nature remains neutral with regard to jurisdictional claims in published maps and institutional affiliations. 